NBER WORKING PAPER SERIES

\title{
GENDER AND ASSIMILATION AMONG MEXICAN AMERICANS
}

\author{
Francine D. Blau \\ Lawrence M. Kahn \\ Working Paper 11512 \\ http://www.nber.org/papers/w11512
}

\author{
NATIONAL BUREAU OF ECONOMIC RESEARCH \\ 1050 Massachusetts Avenue \\ Cambridge, MA 02138 \\ June 2005
}

This is a revised version of a paper prepared for the NBER Mexican Immigration Conference, Cambridge Massachusetts, February 2005. The authors thank the Russell Sage Foundation for research support. We are grateful to Joseph Altonji, George Borjas, and participants at the NBER Mexican Immigration Conference (February 2005) and Pre-Conference (August 2004), in Cambridge Mass., for helpful comments and suggestions, Chris Woodruff for providing us with tabulations of Mexican Census data, and Fidan Kurtulus for collecting labor force participation data. The views expressed herein are those of the author(s) and do not necessarily reflect the views of the National Bureau of Economic Research.

(O2005 by Francine D. Blau and Lawrence M. Kahn. All rights reserved. Short sections of text, not to exceed two paragraphs, may be quoted without explicit permission provided that full credit, including $\odot$ notice, is given to the source. 
Gender and Assimilation Among Mexican Americans

Francine D. Blau and Lawrence M. Kahn

NBER Working Paper No. 11512

July 2005

JEL No. J1, J2, J3, J6

\section{$\underline{\text { ABSTRACT }}$}

Using 1994-2003 CPS data, we study gender and assimilation of Mexican Americans. Source country patterns, particularly the more traditional gender division of labor in the family in Mexico, strongly influence the outcomes and behavior of Mexican immigrants. On arrival in the United States, immigrant women have a higher incidence of marriage (spouse present), higher fertility, and much lower labor supply than comparable white natives; wage differences are smaller than labor supply differences, and smaller than comparable wage gaps for men. Immigrant women's labor supply assimilates dramatically: the ceteris paribus immigrant shortfall is virtually eliminated after twenty years. While men experience moderate wage assimilation, evidence is mixed for women. Rising education in the second generation considerably reduces raw labor supply (especially for women) and wage gaps with nonhispanic whites. Female immigrants' high marriage rates assimilate towards comparable natives', but immigrant women and men remain more likely to be married even after long residence. The remaining ceteris paribus marriage gap is eliminated in the second generation. Immigrants' higher fertility does not assimilate toward the native level, and, while the size of the Mexican American- white native fertility differential declines across generations, it is not eliminated.

Francine D. Blau

School of Industrial and Labor Relations

Cornell University

265 Ives Hall

Ithaca, NY 14853-3901

and NBER

fdb4@cornell.edu
Lawrence M. Kahn

School of Industrial and Labor Relations

Cornell University

264 Ives Hall

Ithaca, NY 14853-3901

1mk12@cornell.edu 


\section{Introduction}

A steady flow of new immigration has led the foreign born share of the US population to rise from 4.8 percent in 1970 to 11.1 percent in 2000. Perhaps more dramatically, the percentage of the accumulated foreign born population that came from Europe or Northern America fell from 70.4 to 18.5 percent between 1970 and 2000, with a corresponding increase in the Asian and Latin American share from 28.3 percent in 1970 to 78.2 percent in 2000 (US Bureau of the Census web site://www.census.gov). By far, the largest source of immigration in recent years has been Mexico. For instance, from 1991 to 2000, 24.7 percent (2.25 million) of the 9.095 million immigrants to the United States came from Mexico, with the next largest source, the Philippines, sending only 5.5 percent $(504,000)$ of the total. And Mexican immigration has been growing in both absolute and relative terms, as immigration from Mexico was 454,000 (13.7\% of the total) in 1961-70. ${ }^{1}$ By 2003, people of Mexican heritage comprised fully $8.2 \%$ of the US adult population, a figure that is about $70 \%$ as large as the incidence of the black nonhispanic population $(11.7 \%) .^{2}$

In addition to making up a large and growing portion of the US population, Mexican Americans are on average poorer and less educated than US residents of European heritage (Browne 1999; Cobb-Clark and Hildebrand 2004). Since it is well known that poverty in the United States falls disproportionately on women and children (Blank 1997), a study of gender and labor market outcomes of Mexican Americans could yield important insights into this issue. And, of particular relevance to the issues considered in this paper, Mexican Americans come from an origin country with a much more traditional division of labor in the family and lower relative and absolute female human capital levels than the United States. For example, female labor force participation rates remain considerably lower in Mexico than in the United States, although the difference has declined in recent years: the Mexican female participation rate was 15.6 percent in 1970 and 39.4 percent in 2000, compared to rates of 41.5 and 58.8 percent in the

\footnotetext{
1 These figures are taken from Department of Homeland Security, Office of Immigration Statistics (2003), Table 2.

2 Based on data from the March 2003 Current Population Survey.
} 
United States (International Labour Organization--ILO website: //laborsta.ilo.org). ${ }^{3}$ Fertility was higher in Mexico than in the United States, although, in this case, the difference has declined considerably in recent years reflecting a sharp drop in fertility in Mexico: the total fertility rate in Mexico was 6.5 total births per woman as of 1970 and 2.8 as of 1998, compared to US rates of 2.5 and 2.1. Adult illiteracy rates for women in Mexico were 22\% in 1980 and $11 \%$ in 1998, compared to male rates of $14 \%$ and $7 \%$ respectively; for the United States, illiteracy was below $5 \%$ in all cases (Blau, Ferber and Winkler 2002, pp. 384-5). Moreover, according to Mexican census data for 1990, among those age 16-65, men averaged 7.0 years of schooling, compared to only 6.4 for women. ${ }^{4}$ Educational attainment rose for both men and women in Mexico between 1990 and 2000: in 2000 men averaged 8.1 years and women 7.6 years. These are of course much lower than average US schooling levels of 13-14 years according to the Current Population Survey (CPS). And, while women's schooling in Mexico grew very slightly faster than men's between 1990 and 2000 (an increase of 1.2 years vs. 1.1 years), a noticeable gender gap in educational attainment among Mexicans remained. In light of these large differences between the labor market status and preparedness of women in Mexico and those in the United States, Mexico represents a potentially interesting case in which to examine the assimilation of women into the US labor market. Do Mexican immigrant families exhibit a more traditional division of labor than US families, as Mexican residents do? To what extent do gender patterns in labor market attachment and success among Mexican Americans converge to US native patterns within and across generations?

In this paper, we use the March CPS Annual Demographic Files for 1994-2003 to study the assimilation of Mexican-American women and men, including both Mexican immigrants and the native born of Mexican heritage. The outcomes we consider include: marriage and fertility,

\footnotetext{
${ }^{3}$ Especially in developing countries, participation rates may be an incomplete measure of economic activity since they often do not count subsistence and family-based activities. It might be argued that an indicator focusing on market-based work is not altogether inappropriate, however, in that it is this type of involvement that is most important in the United States. A measure that implicitly adjusts for these problems (at least to the extent that they affect men and women similarly) is the ratio of female to male participation rates. It tells a similar story: these ratios were .227 (Mexico) and .531 (United States) in 1970, and .472 (Mexico) and .781 (United States) in 2000.

${ }^{4}$ We are grateful to Chris Woodruff for supplying this information from the Mexican census.
} 
labor supply, unemployment, wages, and occupation and industry distribution. The repeated cross-sections in the CPS allow us to examine issues of assimilation among immigrants from a variety of arrival cohorts using the synthetic cohort approach proposed in Borjas (1985).

Moreover, we also study assimilation across generations by analyzing these outcomes for second and third generation Mexican Americans. Examining progress across generations provides a more comprehensive study of assimilation than the traditional immigration literature that has for the most part focused on success at arrival and over time in the United States for those born in other countries. The children of immigrants may do considerably better in the United States than the immigrants themselves, and their fortunes need to be taken into account in evaluating the experience of immigrants (Card, DiNardo and Estes 2000; Card 2004).

We begin by examining outcomes for all Mexican-American adults and then consider married individuals separately. This enables us to confirm our aggregate findings for this group — one that is most likely to manifest traditional labor market patterns. Moreover, while, for the most part, research on immigrants has studied the behavior of individuals, analyzing immigrant behavior in a family context makes sense in general and may be particularly relevant to understanding women's assimilation. Baker and Benjamin (1997) propose a family investment model in which, upon arrival, husbands invest in their human capital, while wives work to provide the family with liquidity during this investment period. With increased time in the destination country, husbands' labor supply increases rapidly due to their growing skills, while wives' labor supply falls off in part because they originally took "dead-end" jobs upon arrival in order to finance their husbands' investments in human capital. Baker and Benjamin provide some evidence consistent with this model using data on Canada over the 1986-91 period. However, using data for the United States from the 1980 and 1990 US Censuses, Blau, Kahn, Moriarty and Souza (2003) did not find evidence consistent with the family migration model. ${ }^{5}$

\footnotetext{
${ }^{5}$ Studies by Long (1980), Duleep and Sanders (1993) and McPherson and Stewart (1989) for the United States are all at least partially consistent with the idea that married immigrant women are more likely to work while their husbands are investing in human capital. However, unlike Blau, Kahn, Moriarty and Souza (2003), each of these studies is based on a single cross-section of data.
} 
Specifically, they find that immigrant husbands and wives both worked less than comparable natives upon arrival and that both had positive assimilation profiles in labor supply, eventually overtaking the labor supply of comparable natives.

In the family migration model, married women are clearly "secondary earners" in the immigrant family. The Blau, Kahn, Moriarty and Souza results for the U.S. suggest more similar economic behavior of men and women within the immigrant family. ${ }^{6}$ Although Blau, Kahn, Moriarty and Souza report that labor supply assimilation patterns for men and women in the United States were very similar for each major sending region, as a group coming from a source country with highly traditional gender roles, it is possible that patterns for Mexican immigrants would more closely approximate the family investment model. Thus we reexamine this question here.

\section{Recent Research on Labor Market Outcomes for Mexican Americans}

Several authors have recently examined the assimilation of Mexican Americans into the US labor market both within and between generations, although none has specifically studied gender differences in the assimilation process or assessed the relevance of the family migration model for Mexican Americans. Trejo (1997 and 2003), for example, studied human capital and wages for men of Mexican origin vs. white, nonhispanic native men for 1979 and 1989 . He found that although men of Mexican origin earned considerably less than whites, most of these differences were explained by the former's relatively low human capital levels. Moreover, while both the relative human capital levels and the return to investment in human capital rose between the first and second generation, this progress stalled between the second and third generations

\footnotetext{
6 In a recent paper, Duleep and Dowhan (2002) use matched Social Security earnings and 1994 CPS data to track the longitudinal earnings growth of immigrant vs. native women. They find that more recent immigrant cohorts' earnings start low relative to natives' but rise quickly with time in the United States and eventually catch up to natives'. In contrast, earlier cohorts' initial earnings were at least as high as natives' but then either increased only a little or actually dropped. The results for the more recent cohorts are similar to the changes in hourly earnings reported by Baker and Benjamin (1997) for Canada and Blau, Kahn, Moriarty and Souza (2003) for the U.S.
} 
(Trejo 1997 and 2003). A cross-sectional study of the wages of men and women for a sample of individuals of Mexican origin by Livingston and Kahn (2002) also found some progress of immigrants between the first and second generations that apparently stalled in the third generation.

Corcoran, Heflin and Reyes (1999) summarize trends in labor market outcomes for Mexican-American women using Census data to compare outcomes for Mexican-American women and white, nonhispanic women over the 1970-90 period. They find that the relative wages and employment attachment of Mexican Americans fell over the 1980s, probably reflecting, in part, the growing immigrant share among Mexican-American women. They also find that, in the cross section, long-term immigrants (i.e., those with over 10 years of US residence) had better wage outcomes and higher employment levels than short-term immigrants, while Mexican-American women born in the United States had higher wages and employment incidence than long-term immigrants, although they still lagged considerably behind white, nonhispanic women in this regard. These findings suggest assimilation across generations and either assimilation among immigrants with more time in the United States or declining labor market success among more recent cohorts of immigrants.

Baker (1999) provides some additional descriptive information on demographic patterns using the 1970, 1980 and 1990 Censuses. Specifically, while immigrant Mexican-American women were in each year roughly equally likely as white, nonhispanic women to be married, USborn Mexican-American women were less likely to be married than white, nonhispanic women. Moreover, Mexican immigrants had more children than white nonhispanics, and so did US-born Mexican-American women. However, these Mexican-white differentials in fertility were smaller for US-born Mexican Americans and also fell progressively from 1970 to 1990 for each nativity group. Relative fertility levels were thus falling for Mexican-American women over time and across generations.

Unlike the earlier work that studied only men or only women, we explicitly analyze gender differences in demographic and labor market outcomes for Mexican Americans. And, in 
contrast to the descriptive studies, we explicitly analyze assimilation in a regression context and may thus estimate how much assimilation occurs in the first generation with exposure to the US economy and labor market, as well as identify the impact of measured covariates vs. behavioral changes in the assimilation of Mexican Americans, both within and across generations. Moreover, unlike the Livingston and Kahn (2002) study of Mexican-origin workers, we make explicit comparisons with a native base group and also examine a much wider array of outcomes than their focus on hourly earnings. And, in contrast to all of these studies, we will also examine the family context in which these outcomes occur. This means, for example, controlling for family related variables in analyzing individual outcomes. In addition, by making explicit gender comparisons, we are able to arrive at conclusions about assimilation with respect to gender roles.

\section{Data and Descriptive Patterns}

We use the 1994-2003 March CPS Annual Demographic Supplement files to study gender and Mexican-American assimilation. These files contain information on the respondent's country of birth, the country(ies) of birth of his/her mother and father, and whether the individual is of Mexican origin. We can thus construct samples of Mexican immigrants, second generation Mexican Americans (defined as individuals who were born in the United States who had at least one parent born in Mexico), and US-born individuals of Mexican origin both of whose parents were born in the United States (the "third generation"). Our comparison group is comprised of third generation, US-born, nonhispanic whites ("nonhispanic whites"). Using ten years of pooled cross-sectional data provides us with fairly large samples of Mexican Americans in each generation (See Appendix Table A1) and allows us to distinguish the impact of immigrant cohort from that of time in the United States (Borjas 1985). ${ }^{7}$

\footnotetext{
${ }^{7}$ As in all analyses based on pooled cross-section data, we cannot observe return migration. Results may be biased if those who remain in the US are a self-selected group of more or less successful immigrants. In addition, there may be recall errors and ambiguities of interpretation among respondents to the CPS question on when they arrived in the United States, since immigrants may enter and leave the United States several times. In a paper analyzing such issues using a recently-developed data base that allows one to correct for such factors (the New Immigrant Survey
} 
Our analyses of intergenerational mobility compare outcomes for immigrants with those of second- and third-generation Mexican Americans. Immigrants observed as of 1994-2003, the time window of our data, may not be representative of the parents of second-generation Mexican Americans also observed at that time, although there is likely to be some overlap. By using the same data to observe all three generations, we are in effect assuming that contemporary Mexican immigrants are in some sense similar to those of the 1950s, 1960s and 1970s when the parents of many of the second-generation Mexican Americans in our sample would have been in the prime working ages. An alternative would be to use data for an earlier period to observe outcomes for the first generation. Each approach has strengths and weaknesses, and recent research suggests they may not produce the same estimates of intergenerational assimilation. For example, Smith (2003) finds more apparent progress in wages and schooling across generations among HispanicAmericans when he pools Census and CPS data for the 1940-1997 period than when he bases his estimate on a single cross section (the 1970 Census).

Looking at one cross-section (or, in our case, a single ten year period) may yield a biased estimate of intergenerational assimilation if unmeasured immigrant cohort characteristics have changed. On the other hand, as Trejo (1997) points out, the time series approach may also be problematic. Between the 1950s-70s and 1994-2003, there were many legal and economic changes that themselves could have influenced the economic success of Mexican-American immigrants. Trejo specifically mentions the passage of the Civil Rights Act of 1964, which outlawed discrimination based on national origin (as well as race and sex). Thus, part of any apparent progress of Mexican Americans in general or Mexican-American women in particular across generations between earlier years and the current period may have been due to changes in the legal and social environment that impacted all generations rather than to assimilation of the second generation. Working in the opposite direction, we may note that rising returns to education and unmeasured skills probably had an independent effect lowering the relative

Pilot--NISP), Redstone and Massey (2004) find that traditional analyses of wages and years of US experience yield similar results under the Census and NISP definition of years in the United States. 
fortunes of most Mexican Americans in the 1990s relative to the earlier period. This development would cause us to underestimate true intergenerational assimilation. ${ }^{8}$ Finally, the prohibition of sex discrimination by the Civil Rights Act is also relevant to our study since we are interested in gender differences in outcomes, as are the considerable changes in social norms and attitudes about gender roles that have occurred since the earlier period. These developments could have had a differential impact on Mexican-American women's labor force behavior and outcomes relative to a native reference group, although the direction of this bias is unclear. Taking into account these considerations, our approach to measuring the intergenerational assimilation of Mexican Americans is to compare all three generations under the same legal, economic and social environment: the 1994-2003 period. However, by looking at estimated immigrant cohort effects, we will be able to simulate outcomes for the immigrants from an earlier cohort and also to assess the extent to which results are sensitive to which immigrant cohort is used in the simulation.

In interpreting our findings for assimilation across generations, special caution is warranted regarding the third generation. While first- and second-generation individuals may be objectively identified in terms of their own, or their parents' place of birth, third-generation, Mexican Americans must self identify themselves as of Mexican origin. If there is self-selection in reporting, results may be biased. ${ }^{9}$ For example, if among third-generation Mexican Americans, those who self-identify as of Mexican origin are less well assimilated than those who do not, assimilation of third-generation, Mexican-Americans relative to the native-born, nonhispanic reference group will be understated..$^{10}$

Table 1 contains some descriptive information on demographic and labor market outcomes for Mexican-Americans and nonhispanic white, third-generation Americans. The entries in Table 1 are predicted levels of these outcomes from regressions controlling for

\footnotetext{
${ }^{8}$ For analyses of the returns to education and unmeasured skills in the context of immigrant assimilation, see LaLonde and Topel (1992) and Borjas (1995).

9 Of course, as noted above, even for immigrants biases may arise due to self-selection in return migration, recall bias, and ambiguities in defining length of residence in the United States.

${ }^{10}$ For a fuller consideration of these issues, see, for example, Duncan and Trejo (2005).
} 
ethnicity/generation, a quartic in age and year. We control for age even at this descriptive stage because there are age differences across samples due to past immigration patterns, and we wish to describe Mexican American-nonhispanic white contrasts net of this compositional factor. ${ }^{11}$ The following regression was estimated separately by gender:

$$
\begin{aligned}
\mathrm{y}_{\mathrm{it}}=\mathrm{b}_{0}+\mathrm{b}_{1} \mathrm{age}_{\mathrm{it}}+\mathrm{b}_{2} \text { age }_{\mathrm{it}}{ }^{2}+\mathrm{b}_{3} \mathrm{age}_{\mathrm{it}}{ }^{3} & +\mathrm{b}_{4} \mathrm{age}_{\mathrm{it}}{ }^{4}+\mathrm{c}_{1} \text { Meximm }_{\mathrm{it}}+\mathrm{c}_{2} \text { Mexsecgen }_{\mathrm{it}} \\
& +\mathrm{c}_{3} \text { Mexthirdgen }_{\mathrm{it}}+\mathrm{d}_{\mathrm{t}}+\mathrm{u}_{\mathrm{it}},
\end{aligned}
$$

where $\mathrm{i}$ indexes individuals and $\mathrm{t}$ indexes survey years and $\mathrm{y}$ is a demographic or labor market outcome, age is the person's age in years, Meximm, Mexsecgen, and Mexthird are, respectively, dummy variables for Mexican immigrants, and second- and third-generation Mexican Americans, $\mathrm{d}$ is a year effect, and $\mathrm{u}$ is a disturbance term. Two versions of equation (1) were estimated: a) one which included all immigrants; and b) one which included only those who migrated to the United States at age 18 or older ("adult immigrants"). ${ }^{12}$ We show results for adult immigrants, in addition to those for all immigrants, because those who migrated as children are likely to be more assimilated to US labor markets than those who migrated as adults (Friedberg 1993). The sample for equation (1) includes only Mexican Americans and thirdgeneration, nonhispanic whites who were age 16-65, and the entries in Table 1 assume the sample mean for age (39 years) and the 2003 year effect. In all regressions and descriptive statistics, we use CPS sampling weights adjusted so that each year receives the same weight. We consider immigrants (or adult immigrants) as a group now for comparison purposes, although later we will discuss the role of immigrant cohort and time in the United States.

\footnotetext{
${ }^{11}$ Within each of the ethnicity/generation subsamples (i.e., third-generation nonhispanic whites, Mexican immigrants, and second- and third-generation Mexican Americans), the average age of men and women was similar, but average age varied across subsamples. Nonhispanic whites averaged 39 years of age, Mexican immigrants 34-35 years (38-39 years for adult immigrants), second generation Mexican-Americans 32 years, and third generation Mexican-Americans 34-35 years.

${ }^{12}$ Results for second- and third-generation Mexican Americans are based on regressions that include all immigrants, although the findings were similar in regressions with the immigrant sample restricted to adult migrants.
} 
The results in Table 1 indicate that, as is well known, Mexican immigrants have much lower levels of schooling than the nonhispanic white reference group: 4.6 to 4.7 years less for all immigrants and 5.5 to 5.6 years for adult immigrants. ${ }^{13}$ Assuming a 10 percent rate of return to education (approximately the rate obtained in our wage regressions reported below), this difference in years of schooling is responsible for a wage differential of .46 to .56 log points (i.e., 58-75 percent), a sizable effect. While less well-educated than nonhispanic white natives, Mexican immigrants appear to be somewhat positively selected relative to the Mexican population. Table 1 shows that among Mexican adult immigrants (who presumably had largely finished their schooling when they arrived in the United States), men and women have 8.3 years of education. ${ }^{14}$ This is higher than the reported years of schooling for men and women in Mexico obtained from Mexican census data for 1990 and 2000: 7.0-8.1 years for males and 6.4-7.6 for females. Moreover, in contrast to the situation in Mexico, Mexican-American men and women immigrants in the US have the same educational attainment. ${ }^{15}$

While Mexican Americans lag behind native nonhispanic whites, there is considerable convergence in education across generations; second-generation Mexican Americans have only 1.07 (males) to 1.19 (females) years less education than the nonhispanic white reference group, while the differentials for the third generation are 1.19 (males) to 1.36 (females) years. The apparent cessation of convergence toward nonhispanic whites' education levels after the second generation is consistent with earlier analyses of labor market outcomes for Mexican-Americans discussed above. In both the second and third generations, the Mexican-American educational shortfall relative to nonhispanic whites is statistically significantly smaller for men than women,

\footnotetext{
${ }^{13}$ We mapped the CPS education categories into years of schooling using Jaeger's (1997) algorithm.

14 We confirmed the claim that adult immigrants had largely finished their schooling: controlling for age, year, immigrant cohort, and years since migration and its square, we found that years living in the US had insignificant and small effects on current education levels for adult immigrant and women.

15 The conclusion that Mexican immigrants are positively selected with respect to education has been challenged by Ibarraran and Lutotsky (2005), who suggest negative selection. On the other hand, Chiquiar and Hanson (2005) find that Mexican immigrants come from the middle and upper-middle portions of the educational distribution, suggesting mildly positive selection. For our purposes, the most important finding is that educational attainment of male and female Mexican immigrants is the same (see below), while in Mexico, men have somewhat more education than women. Thus, Mexican female immigrants are relatively positively selected.
} 
and this gender difference increases from the second to the third generations (from 0.07 to 0.17 ). However, the magnitude of the gender difference in convergence is small—only 0.1 years, and educational attainment of Mexican-American men and women within each generation is virtually identical, in contrast to the $0.5-0.6$ year male advantage in Mexico.

Table 1 shows that, overall, both immigrant men and immigrant women are significantly more likely to be married, spouse present ("married") than are nonhispanic white natives; however, among adult immigrants, men are less likely to be married than the nonhispanic white reference group, while women are still more likely to be married. This suggests that immigration may be disruptive of marriage for Mexican men—either by delaying marriage or causing spouses to live apart—but not for women. Mexican immigrant women are 5 to 7 percentage points more likely to be married than native nonhispanic whites. The higher marriage rates of Mexican immigrant women are consistent with a greater adherence to traditional gender roles in this population, but may also be related to a tendency to migrate jointly with their husbands, perhaps as "tied movers." By the second and third generations, however, Mexican Americans of both sexes are significantly less likely to be married than nonhispanic whites, with differentials of 3-5 percentage points. As discussed by Angrist (2002), reductions across generations in the likelihood of marriage may be due to marital search problems and the desire to marry within one's own ethnic group. ${ }^{16}$ On the other hand, the discrepancy may be explained by measured characteristics, for example the lower levels of education of US-born Mexican Americans. The regression analysis below will shed light on this.

Table 1 also presents results for number of own (biological or adopted) children under age 18 living in the family. While it would be more accurate to have information on number of children ever born, by restricting the age sample for this variable to women no older than 50 and evaluating the variable at age 39, we are likely to obtain a fairly good indicator of cross-group differences in fertility. ${ }^{17}$ Since children who live with only one parent are much more likely to

\footnotetext{
${ }^{16}$ The disproportionately high marriage incidence among immigrant women shown in Tables 1 and 2 for Mexican immigrants is similar to what Angrist (2002) finds for immigrants in general.

${ }^{17}$ Results were similar when the age range was unrestricted.
} 
live with their mothers than their fathers, we restrict our examination of fertility differences to women. Perhaps reflecting higher fertility rates in the source country, Mexican immigrant women have more children than nonhispanic whites, and, although this differential declines across generations, it remains positive even in the third generation. As noted earlier, as of 1998, the total fertility rate for women in Mexico averaged 2.8, while in the United States, the fertility rate was 2.1, a difference of 0.7. While our measure is constructed quite differently, we obtain a very similar differential between Mexican immigrants and nonhispanic whites: Mexican immigrant women average 2.14 to 2.16 children, roughly 0.7 more than the corresponding figure for white nonhispanic women of 1.46. (The gap between the number of own children for Mexican immigrant women and all women residing in the United States was also 0.7.) The gap had fallen to 0.39 by the second and 0.27 by the third generation, suggesting an intergenerational assimilation of roughly $60 \%$.

When we stratified the analysis of the number of children by marital status, we found similar patterns across the generations. For all generations, among either single or married individuals, Mexican Americans have more children, with a declining differential across generations; moreover, the magnitude of the Mexican American-nonhispanic white differential was similar for married and single women. In addition, Mexican-American women were more likely than nonhispanic whites to be single parents, with significant differentials for immigrant (5.3 percentage points), adult immigrant (4.5 percentage points), second-generation (9.6 percentage points), and third-generation Mexican Americans (9.0 percentage points). We expect having larger numbers of children to be associated with less labor market attachment and lower wage offers for Mexican American vs. nonhispanic, white women (Blau, Ferber, and Winkler 2002; Waldfogel 1998).

Table 1 contains several measures of labor force attachment, including whether one is currently employed, total hours of work in the previous year, and whether one is in the labor force. The generational patterns with respect to these three indicators are similar. Among males, immigrants and adult immigrants are roughly equally likely to be currently in the labor force as 
white nonhispanics; in contrast, among females, both groups of immigrants have much lower participation rates than white nonhispanics. The labor force participation rate was 79.2 percent for white nonhispanic women compared to only 53.6 percent for all female immigrants and 50.3 percent for adult female immigrants. However, Mexican-American men's participation decreased by about 5 percentage points between the first and second generations, while that for women rose dramatically, to 72.5 percent. There is little further change for either group between the second and third generations. Thus, by the second generation, Mexican-American women have nearly caught up to nonhispanic white women, and the Mexican American-nonhispanic white difference in the gender gap in participation has been almost eliminated. In the next section we will consider how much of this assimilation to US gender roles occurs among immigrants with time in the United States versus across generations.

The relative labor market attachment of female compared to male Mexican immigrants may be compared to that in Mexico. As noted above, in 2000, the female labor force participation rate was 39.4 percent in Mexico-this was 47.2 percent of the male rate. Mexican female labor force participation rates were 30.2 percent (35.6 percent of the male rate) in 1980 and 34.0 percent (40.7 percent of the male rate) in 1990 (ILO website //laborsta.ilo.org). These earlier rates may be relevant for comparing immigrants who arrived during the 1980s and 1990s. The ILO figures refer to individuals 15 years of age and older, so, for purposes of comparison, we computed raw labor force participation rates for individuals 16 years and older in the CPS with no age cutoff at the top. For all Mexican immigrants, the participation rates were 85.7 percent for men and 46.6 percent for women, for a female-to-male ratio of 54.4 percent; and, for adult Mexican immigrants, the rates were 85.8 percent for men, and 43.3 percent for women, for a ratio of 50.5 percent. These figures show that Mexican immigrant women had higher absolute and relative labor force participation than women in Mexico as of 2000, but the differences were not large.The gap between labor supply of Mexican immigrant women and women in Mexico is somewhat larger if we compare current Mexican immigrants to women in Mexico as of 1980 or 1990. As noted earlier, labor force attachment of women in the United States in general is much 
higher than that of women in Mexican or Mexican immigrants to the United States. In particular, as of 2000, ILO data show that women's labor force participation in the United States was 58.8 percent (81.2 percent of the male rate). This is suggestive of a strong effect of source country patterns on Mexican immigrants in the United States. These observed differences between Mexican immigrants and source country patterns could be a selection effect if migration is selective of relatively more market-oriented women from Mexico; alternatively, exposure to the US labor market may bring Mexican immigrant women into the labor force. Below, we pursue the latter issue in more detail.

Although all the labor supply measures show similar generational patterns, MexicanAmerican employment-population rates are consistently lower relative to nonhispanic, white rates than are their labor force participation rates. This difference reflects the considerably higher unemployment rates of Mexican Americans, especially Mexican-American women, compared to nonhispanic whites, though here too there is dramatic intergenerational convergence for women. Mexican-American male unemployment rates were 2.3-3.2 percentage points higher than those of nonhispanic whites (a large differential, considering nonhispanic white males' predicted rate of 4.7 percent), and there is no intergenerational convergence to native whites' levels. In contrast, the Mexican immigrant women's unemployment rate is 7.5 percentage points higher than nonhispanic whites' (11.4 vs. 3.9 percent), and the female adult immigrant unemployment rate is 8.6 percentage points higher; however, the Mexican American-nonhispanic white gap falls steadily across generations, reaching 4.6 percent by the second generation and 2.6 percent by the third generation. It is possible that Mexican immigrant women have relatively low levels of job seeking skills that prevent their locating a wage offer or that minimum wage floors are especially binding for them. ${ }^{18}$

\footnotetext{
${ }^{18}$ For example, the $25^{\text {th }}$ percentile of hourly wages among all wage and salary workers (both full and part time) with valid wages was only $\$ 5.27$ in 2000 dollars for Mexican-American immigrant women (\$5.11 for adult immigrant women), at a time when the minimum wage ranged from $\$ 4.66$ to $\$ 5.42$ in 2000 dollars; in contrast, the $25^{\text {th }}$ percentile for second and third generation women was $\$ 5.92$ and $\$ 6.14$ respectively. Corresponding figures for Mexican-American men were: $\$ 6.15$ (immigrants), $\$ 6.04$ (adult immigrants), $\$ 6.97$ (second generation) and $\$ 7.47$ (third generation). Thus, the minimum wage cuts into the Mexican immigrant women's wage distribution to a much larger degree than for the other Mexican-American groups.
} 
The final outcome shown in Table 1 is the log of real hourly earnings for full time wage and salary workers. ${ }^{19}$ The immigrant wage shortfalls are very large and roughly the same size for men and women: .505 to $.517 \log$ points for all immigrants and .634 to $.641 \mathrm{log}$ points for adult immigrants. These fall dramatically by the second generation to $.135-.175$ and then rise several $\log$ points to .184-.213 by the third generation. Here we again note the lack of further convergence between the second and third generations noted in previous studies. The male shortfall is 3-4 percent larger than the female shortfall for the second and third generations, implying that the gender wage differential between Mexican Americans born in the United States is somewhat smaller than among nonhispanic whites; this is a fairly general pattern among minorities (Blau, Ferber and Winkler 2002).

\section{Assimilation Within and Across Generations: Basic Regression Results}

One of our key objectives is to compare the degree to which Mexican-American men and women assimilate to US labor market and family patterns, both within and between generations. While Table 1 provides some important descriptive information on demographic and labor market outcomes for immigrants and later generations, in this section we present the results of regression analyses for selected dependent variables that allow us to more explicitly examine assimilation by controlling for the effect of years since migration on immigrants' outcomes and by including additional covariates which control for the human capital and locational characteristics of Mexican Americans. This specification enables us to estimate how much assimilation occurs in the first generation with exposure to the US economy and labor market, as well as to identify the impact of measured covariates vs. behavioral changes in the assimilation of Mexican Americans, both within and across generations.

Specifically, to capture the assimilation of immigrants, we augment equation (1) by replacing the immigrant dummy variable with a full set of immigrant arrival cohort dummies,

\footnotetext{
19 See the appendix for the construction of the earnings variable.
} 
and an indicator of years since migration and its square. The cohort variables refer to arrival before $1961 ; 1961-70 ; 1971-80 ; 1981-90 ; 1991-96$; and 1997-2002. As noted above, since we are pooling ten years of data, we can in principle distinguish the effects of different arrival cohorts from that of time in the United States as in Borjas (1985). In our basic models, we also control for human capital (years of schooling) and location (eight Census region dummies, an msa dummy, and dummies for California and Texas, the two states with the largest incidence of Mexican Americans in the population ${ }^{20}$ ), in addition to a quartic in age and year dummies (as above). For comparison, we also estimate models with only the age and year controls, in effect allowing human capital and region to be endogenous.

With respect to immigrants, the two specifications allow us to compare immigrants both to third-generation nonhispanic whites in general and also to those with similar measured characteristics, with the former comparison including both compositional and behavioral differences and the latter attempting to isolate the effect of behavioral differences. Similarly, looking across generations, comparison of the two specifications allows us to make inferences about the degree to which assimilation in labor market and family outcomes occurs through changes in the education and location variables vs. behavioral changes. Table 2 shows regression results controlling for education and location as well as year, while Appendix Table A2 shows corresponding results for models that control only for age and year. Means of the explanatory variables are shown in Table A3. To assist in the interpretation of the regression results, Figures 1-6 show implied assimilation profiles for Mexican Americans. Immigrant outcomes are usually evaluated for the 1971-80 arrival cohort. We chose this cohort because it likely contains a large number of the parents of second-generation Mexican Americans in our 1994-2003 sample period. However, where relevant, we also discuss other arrival cohorts, particularly the 1980s cohort,

${ }^{20}$ California and Texas dummies were used by Trejo (1997 and 2003) in his analyses of Mexican-American men. In addition, Ibarraran and Lubotsky (2005) suggest that the US Census overstates educational attainment for Mexican immigrants. If this is true, then the results we show in Figures 1-9 with full controls may be suspect. However, we note that all of our estimated immigrant assimilation profiles have similar slopes whether or not we control for education (and region). Thus, our basic conclusions about the direction and magnitude of immigrant assimilation are likely to be robust with respect to this possible measurement error in immigrant education. 
since this was a period of rapidly rising returns to education, a factor that worked against the labor market success of Mexican Americans.

Turning first to the incidence of marriage shown in Table 2 and Figures 1a and 1b, we see that, upon arrival, Mexican immigrant men are less likely and Mexican immigrant women more likely than otherwise similar nonhispanic white natives to be married, spouse present. There is some assimilation for both sexes, with substantial male assimilation into marriage among immigrants with time in the United States, and some reduction over time in females' likelihood of being married. This pattern suggests that, for males, immigration may be disruptive of marriage (either by delaying marriage or causing a temporary separation from their wives), whereas marriage may play a positive role in immigration decision of women, with some perhaps arriving as tied movers. Despite assimilation towards the lower marriage incidence of natives with similar characteristics, female immigrants continue to be more likely to be married, spouse present, than the native reference group for all cohorts. For example, the 1971-80 arrival cohort of immigrant women has an 18.2 percentage point higher incidence of marriage upon arrival in the United States than the native reference group, and continued to have an 8.4 percentage point advantage after 20 years of residence. Given their positive assimilation, male immigrants in this cohort were projected to overtake their native counterparts after 8 years and to have an 11.0 percentage point higher incidence of marriage after 20 years. Thus, both male and female immigrants are characterized by more traditional marriage patterns than natives. The regression results suggest however that full assimilation to the marriage patterns of otherwise similar thirdgeneration, nonhispanic whites has occurred by the second generation in which Mexican Americans of both sexes are roughly equally likely to be married as comparable natives; by the third generation Mexican-American women are actually slightly (3 percentage points) less likely to be married than the reference group.

Assimilation rates are similar when we do not control for education and location. However, as may be seen in Figures 1a and $1 \mathrm{~b}$ (see also Tables 2 and A2 ), the characteristics of Mexican Americans lower their marriage propensity. Specifically, we find that education raises 
the incidence of marriage, while residence in an MSA, or in California or Texas lowers it, and Mexican Americans have lower levels of schooling and are more likely to live in California or Texas and in MSAs (Table A4). Nonetheless, as may be seen in Figure 1b, female immigrants in the 1971-80 arrival cohort remain more likely to be married than natives, even when these controls are omitted. (This is the case for other arrival cohorts as well.) Considering subsequent generations, it appears that education and location factors, rather than a dearth of prospective partners, are sufficient to account for the lower raw marriage rates of second- and thirdgeneration Mexican Americans compared to third-generation, nonhispanic whites observed in Table 1 and Figures 1a and 1b, since, as we have seen, the Mexican American-nonhispanic white differences are virtually eliminated when we control for these factors.

Consistent with higher fertility rates in Mexico than in the United States, Table 2 indicates that Mexican immigrant women in all cohorts are estimated to have higher fertility than otherwise comparable natives upon arrival in the United States when marital status is not controlled for. The immigrant-native differential upon arrival has been declining with successive arrival cohorts. This trend tracks the sharp declines in fertility that have occurred in Mexico. Some of the immigrant-native differential is due to the greater propensity of immigrant women to be married. Controlling for marital status reduces the estimated immigrant-native differential substantially; however, with the exception of the most recent arrival cohort, immigrants continue to have higher fertility than the reference group, even controlling for marital status. Immigrant women's fertility is found to increase relative to natives with time in the United States: Table 2 shows significantly positive assimilation profiles for immigrant women in both specifications (see also Figure 2). Thus, like Blau (1992), we find evidence consistent with the notion that that the immigration process disrupts or delays fertility, and thus that immigrant women's fertility increases over time in the United States relative to comparable native women-in this case further widening the immigrant-native fertility differential over time. For the 1971-80 arrival cohort, controlling for education and location, immigrants are estimated to arrive with .26 more children than natives, and this gap rises to .70 children after 20 years of residence. The 
immigrant-native differences in fertility are larger—rising from .42 to .83 after 20 years_for the model that does not control for education and location, a result consistent with a negative relationship between fertility and education. Note that, as Blau (1992) points out, if the immigration process disrupts fertility, the positive effect on fertility of years since migration does not necessarily mean that no assimilation toward native fertility levels is taking place. That is, the desired number of children could potentially have been reduced by exposure to US norms and labor market opportunities but fertility nonetheless rises over time compared to natives as desired fertility is approached. The problem is that we do not observe desired fertility.

While, consistent with more traditional gender roles, Mexican immigrant women are a high fertility group relative to the native reference group, with no direct evidence of assimilation towards native levels, there is clear evidence of intergenerational assimilation of MexicanAmerican fertility toward nonhispanic white levels. Mexican-American fertility does remain higher, however: .37 higher for the second generation and .24 higher for the third generation, even controlling for measured covariates. These differences relative to nonhispanic whites are only slightly affected by whether we control for education (and location), presumably reflecting the smaller education differentials relative to nonhispanic whites for Mexican Americans born in the United States compared to Mexican immigrants.

As may be seen in Table 2 and Figures $3 a$ and 3b, upon arrival, the labor supply patterns of Mexican immigrants are much more traditional than those of otherwise similar natives in the reference group. We focus here on annual work hours, including those who worked zero hours, since this variable summarizes both labor force participation and work intensity. Upon arrival, immigrant women's annual hours are considerably lower than those of the reference group, while, for cohorts arriving after 1970, men's annual hours are somewhat higher. More recent cohorts of immigrant men increased the hours differential compared to the native reference group, ceteris paribus, while, consistent with rising female labor force participation in Mexico. the gap for women decreased a bit, though the pattern is much less pronounced than we found for fertility and the shortfall compared to the native reference group remains sizable. Unlike our 
results for marriage and fertility, however, we find substantial assimilation of immigrant women to the native reference group's labor supply patterns. Despite their initially higher levels, male hours show some positive assimilation as well.

Focusing on the dramatic results for women, we see that, upon arrival in the United States, the 1971-80 cohort of immigrant women worked a highly significant 455 fewer hours than comparable white nonhispanics, a large gap compared to the white nonhispanic average of 1281 hours per year. However, there is rapid assimilation: over half of this shortfall is eliminated after ten years, as the gap falls to 219 hours; and nearly all of the rest after 20 years in the United States when immigrants are estimated to work only 31 hours less. In results not controlling for schooling or location, the labor supply effects for immigrants become much more negative, but the assimilation profiles have similar slopes to those in the models with full controls (see also Table A2). For example, immigrant women in the 1971-80 arrival cohort initially work 839 hours less; after 20 years, this deficit is reduced to 405 hours. Immigrants' low levels of education thus cause them to work much less than white nonhispanic natives of the same age.

Across generations, Mexican-American men appear to be progressively less workoriented than comparable nonhispanic whites (Table 2 and Figure 3a), with a 105 hour shortfall by the third generation. In contrast, second- and third-generation Mexican American women work about the same number of hours as comparable white nonhispanics: the effects range from a 14 hour shortfall for the second generation that is insignificant to a 21 hour shortfall for the third generation that is significant although still small compared to the average white nonhispanic female labor supply of 1281 hours (Table 2 and Figure $3 \mathrm{~b}$ ). As we have seen, our estimates suggest that the assimilation to the labor supply patterns of otherwise similar women in the white nonhispanic reference group essentially occurs in the first generation. As was the case for immigrants, when we do not control for education or location (see alsoTable A2), the MexicanAmerican hours effects become more negative for the second and third generation compared to models with full controls, although the changes in these effects are smaller than for immigrants 
(due to later generations' higher education levels). The hours shortfalls for US-born Mexican Americans range from 148 to 177 hours for men and from 112 to 122 hours for women.

The most striking findings in these results is the dramatic assimilation of Mexican immigrant women into the US labor market and the relatively rapid erosion of the highly traditional labor supply pattern exhibited by Mexican immigrants upon arrival in the United States. Female immigrants begin with a large ceteris paribus shortfall in work hours. However, within 20 years of residence, their work hours are nearly equal to those of women with the same characteristics in the third-generation, nonhispanic white reference group; and this remains the case in the second and third generations. While male immigrants tend to work more than the reference group, ceteris paribus, this is no longer the case in subsequent generations. Thus, by the second generation, the labor supply patterns of Mexican Americans exhibit no more gender specialization than do those of third-generation, nonhispanic whites, all else equal. Even without controlling for education, there is still rapid assimilation of Mexican immigrant women into work with time in the United States, although a sizable labor supply gap remains. The assimilation process continues across generations as US-born Mexican origin women raise their education levels relative to the reference group. However, shortfalls remain for both men and women that are roughly constant between the second and third generations, suggesting a lack of further convergence in annual hours beyond the second generation, a pattern noted in previous work and for other dependent variables.

Although the annual hours measure indirectly reflects Mexican American-nonhispanic white differences in unemployment, we also examine unemployment rates explicitly because they may provide evidence on particular labor market problems facing Mexican Americans. Like the labor supply measure, the unemployment experience of Mexican immigrants differs greatly by sex (see Table 2 and Figures 4a and 4b). For males the immigrant-native difference, controlling for characteristics, tends to be small and men in recent cohorts actually have a lower unemployment rate at arrival than comparable white nonhispanics. There is no significant effect of years since migration on the unemployment rates of immigrant men, and second- and third- 
generation, Mexican-American men actually have 1.7-1.9 percentage points’ higher unemployment than comparable white nonhispanics.

In contrast, immigrant women have a substantially higher unemployment rate than comparable natives at arrival, but this gap decreases somewhat across cohorts. The somewhat smaller unemployment gap for more recent arrival cohorts corresponds to the cross-cohort decline we found for labor supply (in turn likely reflecting rising female participation rates in Mexico) and suggests that a portion of the unemployment gap reflects job seeking skills. The stronger results are for the years since migration variable, which indicate that the unemployment gap falls substantially with time in the United States. For example, in the 1971-80 cohort, Mexican immigrant women have a 10.3 percentage point higher unemployment rate at arrival than comparable white nonhispanic natives. After ten years in the United States, however, the gap has fallen to 6.4 percentage points; and after 20 years to 3.0 percentage points. Little further assimilation occurs generations, controlling for measured characteristics: the gap is 3.4 percentage points for the second generation and 1.5 percentage points by the third generation. When we control only for age and year, the immigrant-native difference in unemployment rates for women is much larger and remains considerable even after long residence, although substantial assimilation does take place. For example, the unemployment rate of immigrants in the 1971-80 cohort is 14.3 percentage points higher upon arrival in the United States and is still 6.5 percentage points higher after 20 years of residence. The differential decreases to 4.7 percentage points in the second generation and 2.6 percentage points in the third generation.

We now turn to the results for wage assimilation in Table 2. Given the deteriorating wage position of immigrants, we have evaluated the regression results for both the 1971-80 (Figures 5a and 5b) and 1981-90 (Figures 6a and 6b) arrival cohorts. The results for immigrant men conform to what would be expected based on the literature. There is a considerable wage gap with otherwise similar natives at arrival that tends to increase across cohorts, as well as some weak evidence of positive wage assimilation with time in the United States. The wage gap for men in the 1971-80 (1981-90) cohort is estimated to be $.17(.28) \log$ points on arrival and to fall 
to $.12(.23) \log$ points after 20 years of residence. The shortfall for immigrants in the 1971-80 cohort after 20 years in the United States was comparable to the estimated wage gaps for the second and third generations of .13-.14 log points, although that estimated for the 1981-90 cohort is higher.

The arrival shortfalls for women also tend to increase over time and were .07 log points for the 1971-80 cohort and .16 log points for the 1981-90 cohort. In general, the arrival shortfalls tend to be smaller than for men, a pattern we noted above for later generations as well. However, for women immigrants, there is no evidence of positive wage assimilation. Moreover, for women, as for men, we find little further wage assimilation across generations compared to the 1971-80 arrival cohort of immigrants, controlling for education and location, with a wage gap of .08-.09 for the second and third generations. And, similar to men, some intergenerational wage assimilation is suggested for the 1981-90 cohort.

The absence of wage assimilation for immigrant women may reflect the limitations of our successive cross-sections for mapping the true longitudinal patterns, although it may be noted that evidence of wage assimilation is not particularly strong for men either. Given strong positive assimilation for labor supply, the women in the wage sample in successive years since migration groups will include more new entrants with relatively little labor market experience and hence low wages. They may be a less positively selected group in other ways as well. This is may be the reason for the seeming lack of wage assimilation for women. We investigated this possibility by implementing a Heckman (1979)-style selectivity bias correction for women's wages. For this analysis, we considered all those with valid wage observations (i.e. full time and part time workers) as the wage sample. We identified the selection equation (a probit on a variable equaling one if the respondent was in the wage sample) by excluding marital status, number of children less than 6 years old, and number of children between 7 and 17 years old from the wage equation. Ordinary least squares wage equations showed immigrant arrival effects that were negative for all cohorts except 1971-80 and ranged from 0.035 to -0.093, with some of the negative values significant. Moreover, there was marginally significant negative female 
immigrant wage assimilation, where wages fell $0.068 \log$ points over 20 years, all else equal. ${ }^{21}$ However, when we implemented the selectivity bias correction, immigrant arrival effects ranged from -0.085 to -0.207 and were significant in almost every case. More importantly, there was some evidence of positive wage assimilation for women: after 20 years, wages rose $0.054 \log$ points, ceteris paribus, although this effect was not significant. Thus, there is some weak evidence that selectivity may help explain the seeming lack of female wage assimilation among observed workers; however, this conclusion is tentative, since identification of the selection equation required some strong assumptions.

Figures $5 \mathrm{a}, 5 \mathrm{~b}, 6 \mathrm{a}$ and $6 \mathrm{~b}$, as well as Table A2, show that the wage shortfalls of each Mexican-American group are much larger when the controls for education and location are omitted; this of course reflects the lower educational attainment of Mexican Americans relative to the reference group of third generation nonhispanic whites. Viewing the data in this way, however, does give a more substantial role for intergenerational wage assimilation due to the increasing educational attainment of Mexican Americans across generations. So, for example, in the 1971-80 cohort, controlling only for age and year, even after 20 years in the United States, the pay shortfalls for immigrants are much larger than for later generations: .48 log points for immigrant men and $.44 \log$ points for immigrant women versus .18-.21 log points for men and .14-.19 log points for women for later generations. Thus, the increase in education achieved by subsequent generations of Mexican Americans relative to immigrants leads to a substantial closing of the raw pay gap relative to third-generation white nonhispanics. However, we again note a lack of further convergence, in this case for log wages, beyond the second generation.

The results considered above may be biased by changes in the age composition of a specific immigration cohort across successive cross sections (Friedberg 1993). Specifically, more recent cross sections will include more immigrants in the particular cohort who immigrated as children. The assimilation process is likely to be quite different for those who immigrated as

${ }^{21}$ The arrival effects are less negative, and the assimilation slope is more negative for the pooled full time and part time sample than for the full time sample shown in Table 2 and Figures $5 \mathrm{~b}$ and $6 \mathrm{~b}$. In both cases, however, using observed workers shows a lack of positive assimilation among Mexican immigrant women. 
children compared to adult immigrants. For this reason we repeated the analyses in Table 2 with the immigrant sample restricted to adult immigrants (see, Table A4). The results were very similar. One exception was that there was somewhat more positive assimilation with time in the United States for men's annual work hours; however, even here, the relationship was much steeper for immigrant women than men.

In addition to analyzing wages and employment, we also show some evidence on the industrial and occupational progression of Mexican-Americans within and across generations. Sectoral representation can be an important indicator of the degree of integration into American society. Table A5 shows the actual distributions of workers across occupations and industries, while Tables 3 and 4 show industry and occupation segregation indexes by gender (Table 3 ) and ethnicity (Table 4). ${ }^{22}$ We distinguish immigrants according to whether they migrated as adults, and we also show separate statistics for immigrants who were in the United States at least 10 years. Comparing these long-term immigrants to the overall immigrant sample shows the combined effects of time in the United States as well as selective return migration and changing cohort characteristics.

Looking first at industry distribution, one of the most dramatic differences between Mexican immigrants and the white nonhispanic reference group is that Mexican immigrants, especially men, are much more likely to work in agriculture. However, by the second generation, the Mexican-American female incidence of farm work is virtually the same as for nonhispanic whites, while that for Mexican-American men is only slightly higher than that of nonhispanic white men. And by the third generation, male agricultural employment is virtually indistinguishable from that of nonhispanic whites. There is also a dramatic cross-generation movement of Mexican-American women out of nondurable manufacturing into health and

\footnotetext{
22 In 2003, there was a major change in CPS occupation and industry codes based on the changes in these codes adopted in the 2000 Census. Crosswalk information available at the Census web site (http://www.census.gov/hhes/www/ioindex/crosswalks.html) was used to assign incumbents in the 2003 CPS to the 1990 Census categories employed in earlier CPS's on the basis of the category into which the largest number of individuals in their detailed occupation or industry would have been allocated.
} 
education services. A similar but less dramatic development also characterizes the movement of Mexican-American men across generations out of construction.

Regarding occupations, there is a notable movement across generations of MexicanAmerican men out of personal service, farmworker and operative jobs into managerial and professional jobs. For women, there is a dramatic move out of operative and personal service jobs into managerial, professional, and especially clerical occupations. While most of this occupational movement occurs across generations, there appears also to be some upgrading of immigrants with time in the United States, as suggested by the results for long-term vs. all immigrants. Of course, these latter differences may also be due to cohort effects or selective return migration.

Tables 3 and 4 summarize the impact of these occupational and industrial shifts on segregation indexes. ${ }^{23}$ First, Table 3 shows that differences in industry segregation by gender between Mexican Americans and the nonhispanic white native reference group are not very large. The level of industry segregation by gender of immigrants is very similar to to that of nonhispanic whites; and there is actually a slight increase in gender segregation by industry across generations. The differences between Mexican Americans and the reference group in occupational segregation are larger and exhibit an interesting cross generational pattern. Among immigrants, there is only slightly more occupational segregation by gender than nonhispanic white natives. However, the occupational segregation index rises steadily across generations of Mexican Americans.

The results in Table 4, which show segregation indexes by ethnicity, shed some light on the rising gender segregation across generations for Mexican Americans. For industry and especially occupation, there is a more dramatic reduction across generations in segregation vs. nonhispanic whites for Mexican-American women than men. Specifically, the industrial

\footnotetext{
${ }^{23}$ The segregation index is defined as the fraction of the male or female work force that would have to change jobs in order to achieve parity. For example, for gender, it is equal to $.5^{*} \Sigma_{\mathrm{i}} \mid \mathrm{m}_{\mathrm{i}}-\mathrm{f}_{\mathrm{i}}$ l, where i represents sector (occupation or industry), and $\mathrm{m}_{\mathrm{i}}$ and $\mathrm{f}_{\mathrm{i}}$ are respectively the proportions of the total male and female work force employed in sector $\mathrm{i}$. As elsewhere, the reference group for the analysis by ethnicity is white nonhispanic natives.
} 
segregation index (Mexican-Americans vs. nonhispanic whites) falls 25.8 percentage points for immigrants as a whole to the third generation for women but only 18.5 percentage points for men, while the occupational segregation index falls 35.6 percentage points for women but only 22.6 percentage points for men. The result is a slight increase in gender segregation by industry and a more substantial one by occupation. Focusing on the latter increase, Table A5 shows that Mexican-American men have moved into white collar jobs to a lesser extent than MexicanAmerican women have. For example, Table A5 shows that $11.8 \%$ of Mexican immigrant men and $28.0 \%$ of Mexican immigrant women worked in the managerial, professional, clerical or sales jobs; by the third generation, these figures were $34.7 \%$ for men and fully $68.8 \%$ for women. $^{24}$

\section{The Family Migration Model: Regression Results}

Our data can be used to study the relevance of the family migration model for MexicanAmerican immigrants. This exercise is additionally of interest because it enables us to ascertain whether we obtain similar findings to those above when we focus on married individuals and explicitly take into account spouses' characteristics. To address these questions, we constructed a file using the CPS data that consisted of married individuals for whom we could identify the ethnicity and nativity of both husband and wife. We restricted the sample to women (men) who were of Mexican origin and to a reference group of women (men) who were themselves thirdgeneration, white nonhispanics and were married to third-generation, white nonhispanics. (The latter constitute the reference category in the female and male regressions.)

\footnotetext{
24 Tables 4 and A5 also show that the occupation and industry distribution of adult immigrants is more dissimilar to nonhispanic whites than is the case for immigrants in general and that, among immigrants, there is more integration (relative to nonhispanic whites) among long-term immigrants than for the immigrant group as a whole. (This latter pattern is especially pronounced for the "all immigrants" group). These patterns for adult immigrants are consistent with their larger educational shortfalls, while those for long-term immigrants may be due to assimilation, cohort effects, or selective return migration.
} 
As may be seen in Table 5, Mexican Americans of both sexes have a very high probability — 82 to 83 percent—of having a Mexican-American spouse. This incidence is particularly high for immigrants, with 92 percent of both men and women having a spouse who is of Mexican origin. Fully 84 percent of female immigrants and 79 percent of male immigrants have spouses who are themselves Mexican immigrants. Although we do not know when these marriages took place, the higher percentage of female than male Mexican immigrants whose spouse is a Mexican immigrant is consistent with our finding above that immigration tends to be a family decision for women and that the incidence of being married (spouse present) is high upon arrival in the United States. Of course, marriages to fellow immigrants may also occur in the United States or involve bringing a spouse to the United States from Mexico. The probability of having a spouse who is of Mexican origin declines across generations for both women and men: decreasing from 92 percent for immigrants to 74 (70) percent for second-generation women (men), and 70 (66) percent for third-generation women (men). Nonetheless, marriage outside the Mexican-origin group still characterizes only 30-34 percent of third-generation, married Mexican Americans. ${ }^{25}$

Table 6 contains selected regression results for three dependent variables that are of central importance in forming a picture of married women's assimilation and evaluating the family investment hypotheses: the number of children for married women and annual work hours and log hourly earnings for married women and married men. The explanatory variables include both own and spouse characteristics for education, age, migration cohort, and years since migration. In addition, there is a full set of shift terms for each combination of own and spouse Mexican-American generation, as well as dummies for spouse's race and ethnicity. Based on these regressions, Figures 7-9 show assimilation profiles for Mexican immigrant women and men with an immigrant spouse who came to the United States at the same time.

\footnotetext{
25 We again note, however, that third-generation Mexican Americans must self-identify. Marriage outside the Mexican-American community may reduce their propensity to self-identify as Mexican American, or at least be correlated with a reduced propensity to so identify. Again see, Duncan and Trejo (2005).
} 
We begin by considering the results for annual hours, which are the key variable for the family investment hypothesis, and also the variable for which we obtained the most striking evidence of assimilation for the full sample of Mexican-American women. As may be seen in the table and Figure 7, the results for married women are quite similar to those for the full female population and thus do not support the family migration model. Married immigrant women tend to have large ceteris paribus labor supply shortfalls upon arrival in the United States and steep positive assimilation with time in the United States. So for example, married women in the 1971-80 arrival cohort who have a Mexican immigrant spouse who arrived in the same period are estimated to supply 556 hours less per year when they first come to the United States; however, after ten years in the United States, the shortfall has been reduced by more than half to 265 hours, and after 20 years, to only 36 hours. Immigrant men also have an hours shortfall at arrival and positive assimilation profiles; however, these are both less dramatic than for women: for married men who migrated with a Mexican spouse, the arrival hours shortfall for the 1971-80 cohort is 272 hours, a differential that falls to 109 hours after 10 years and actually becomes a 4 hour excess after twenty years. In earlier work using 1980 and 1990 Census data (Blau, Kahn, Moriarty and Souza 2003), we showed that, among immigrants to the United States in general, married men and women had similarly steep assimilation profiles relative to average hours worked by natives. Mexican immigrants in the 1990s and early 2000s stand out from this pattern in that the profile is much steeper for women than men.

Second- and third-generation, Mexican-American women married to second- or thirdgeneration Mexican-American men have smaller deficits (or in some cases, slightly higher work hours) relative to comparable white natives than immigrants from the 1971-80 cohort at arrival or after ten years in the United States-Table 6 shows hours effects of -8 to +100 work hours relative to the white nonhispanic reference group. However, as in the case of the full sample, most of the convergence in labor supply patterns to otherwise similar individuals in the white nonhispanic reference groups occurs in the first generation. 
Turning to assimilation in log wages we again find similar patterns to those observed for the full sample (see Table 6). Figure 8 shows results for immigrant men and women who migrated from Mexico with their spouse in the 1971-80 or 1981-90 period. Except for women in the 1971-80 arrival cohort, we see large wage deficits with otherwise similar native, nonhispanic whites in the reference group, and wage profiles for the 1981-90 cohort are considerably lower than those for the 1971-80 cohort. As in the full sample, while men's wages rise with time in the United States (wage assimilation is actually steeper for married men than for the full sample), there is no evidence of positive wage assimilation for women. This pattern is consistent with the family migration model in that men appear to be investing in their own human capital, while women's wages are seemingly not affected by time in the United States. The same reasoning we used earlier about the potential effects of selectivity on immigrant women's wage assimilation applies here. Specifically, it is possible that women with longer US residence are likely to include more recent labor force entrants with less experience and may be less positively selected than the female sample of full time workers among recent arrivals. However, unlike our earlier results with married and single women pooled, when we implemented Heckman (1979) selectivity bias correction techniques for married women (identified this time by the exclusion of number of children under 6 and number of children between 6 and 17 years old), we still did not find any evidence of positive wage assimilation for immigrant women. ${ }^{26}$

As above, we do not find much evidence of wage convergence across generations, controlling for measured characteristics. For example, for immigrant men from the 1971-80 (1981-90) arrival cohort the wage deficit relative to the white nonhispanic reference group falls from .29 (.43) log points at arrival to $.14(.28)$ after 20 years. For second- and third-generation men married to US-born, Mexican origin women, the pay shortfall for men ranges from .15 to $.21 \log$ points, suggesting some evidence of moderate wage assimilation only for the 1981-90 cohort. For women in the 1971-80 cohort, there is hardly any wage gap relative to comparable

\footnotetext{
${ }^{26}$ In both Table 6 and in the selectivity-bias corrected results, there was a modestly negative, insignificant wage profile for immigrant women who migrated with their husbands.
} 
white nonhispanics. But for women in the 1981-90 cohort, the gaps are .17 log points at arrival and $.20 \log$ points after 20 years. Mexican-American women of later generations married to USborn Mexican origin men have ceteris paribus log wage deficits of .06 to .12 relative to white nonhispanics. Again, little intergenerational assimilation is implied for the 1971-80 cohort and some modest improvement across generations is suggested for the 1981-90 cohort.

Finally, we may consider evidence of the assimilation in fertility. As was the case for the full sample, married Mexican immigrant women (who migrated with a Mexican spouse) tend to have more children than their counterparts upon arrival in the United States, though this difference has been declining with successive cohorts and has recently become negative. Fertility compared to otherwise similar individuals in the white nonhispanic reference group then increases further with time in the United States. (Note the own and spouse cohort and ysm effects must be summed to make this comparison.) For example, in the 1971-80 cohort, women have somewhat more (.19) children than comparable white nonhispanic women upon arrival, a gap that rises to .76 after 20 years in the United States. The 1997-2002 cohort that begins with .075 fewer children than comparable white nonhispanics, is estimated to have .50 more children after 20 years. The relative fertility of second- and third-generation, Mexican-American women in Mexican-American families falls to .22 to .34 (second generation), and .25 to .34 (third generation). However, based on the declining relative fertility of newer cohorts of immigrants, we might expect excess fertility of future second- and third-generation Mexican-American women to be even smaller than this.

The positive relationship between fertility and time in the United States that we obtain for immigrants is illustrated in Figure 9 for the 1971-80 arrival cohort. This relationship could be consistent with the family investment model: fertility may be deferred while wives' focus on the labor market in order to support their husband's human capital investments. However, this is unlikely given the strong positive assimilation that we have found for wives' labor supply. In light of this, we believe that the pattern of fertility most likely represents a disruption of fertility due to immigration. One factor leading the family to defer fertility may be a desire to postpone at 
least some childbearing to a time when the family is on a firmer financial footing. But, again, given the labor supply patterns we observe, this is likely to be a time when both spouses are faring better in terms of labor market incomes.

\section{Conclusions}

This paper has examined gender and the labor market and demographic assimilation of Mexican Americans, both within and across generations. Published data show a much more traditional gender division of labor in the family in Mexico than in the United States, with women in Mexico having considerably lower labor force participation and higher fertility than those in the United States, as well as lower education both absolutely and relative to Mexican men. Our data suggest that these source country patterns strongly influence the outcomes and behavior of Mexican immigrants on arrival in the United States. Both male and female immigrants have much lower levels of education than the native reference group (thirdgeneration, nonhispanic whites), although immigrants of both sexes have somewhat higher levels of education than the average for Mexico and gender differences in educational attainment among immigrants are minimal. Educational attainment of Mexican-American men and women increases substantially between the first and second generations, but not beyond. Controlling for education and other characteristics including location, on arrival in the United States, immigrant women are more likely to be married spouse present, have higher fertility, and much lower labor supply than the native reference group. The key question then is how these patterns change with time in the United States of immigrants and over the second and third generations.

Our most striking finding is the dramatic assimilation in labor supply for female immigrants with time in the United States. For example, upon arrival in the United States, the 1971-80 cohort of Mexican women had a ceteris paribus shortfall of 455 hours relative to nonhispanic whites; this fell to 219 hours after ten years of residence and 31 hours after twenty years. The gap remained small in the second and third generations. Consistent with a more 
traditional division of labor in the first generation, immigrant men's annual hours tended to be somewhat higher than those of nonhispanic whites upon arrival, all else equal, and showed moderate positive assimilation with time in the United States. In contrast, Mexican-American men in later generations actually have somewhat lower labor supply than natives. Taking the male and female results together, Mexican American-nonhispanic white differences in gender specialization in labor supply are very small for long-term immigrants and are entirely eliminated by the second generation.

When we do not control for education and other characteristics, however, immigrants, as a low education group, have hours shortfalls relative to nonhispanic whites for both men and women; the gaps are quite sizable for women and remain large, even with positive assimilation in hours. In the case of women, particularly, there is assimilation between the first and second generation, due to the rising educational attainment, but no further progress between the second and third generation.

Wage differences between female immigrants and nonhispanic whites, controlling for other factors, are far less marked than labor supply differences and tend to be smaller than the immigrant-nonhispanic white wage gap for men, though both show a deteriorating wage position of immigrants beginning in the 1980s. While male wage gaps decline moderately with exposure to the US labor market, in contrast to the labor supply results, we find no evidence of positive wage assimilation for women. This may reflect the limitations of the synthetic cohort approach. Positive assimilation in employment means that, as years since migration increase, the wage sample likely includes more new labor market entrants and may be less positively selected in other ways as well. We present some evidence based on a correction for selectivity bias that is consistent with this reasoning, although wage assimilation, even based on these analyses, is quite moderate. For both men and women, rising educational attainment in subsequent generations contributes to a considerable narrowing of the raw wage gap with nonhispanic whites, but we again find no evidence of convergence beyond the second generation. The lack of further assimilation between the second and third generation thus characterizes our findings for 
education, labor supply and wages and mirrors results from some earlier studies of Mexican Americans.

Results for assimilation on the demographic outcomes are also mixed. Over time in the United States, female immigrants assimilate towards the native reference group but remain more likely to be married, ceteris paribus. While male immigrants are actually less likely to be married spouse present than otherwise similar nonhispanic whites upon arrival, their marriage incidence increases with time in the United States and, after long residence, they are predicted to be more likely to be married than natives. Across generations, both male and female immigrants assimilate to the patterns in the native nonhispanic white reference group, controlling for characteristics including education, and are no more likely to be married. When controls for education and other characteristics are omitted, second- and third-generation, Mexican-American men and women are both less likely to be married than nonhispanic whites.

While immigrant women have higher fertility than nonhispanic whites, all else equal, the immigrant-native differential upon arrival has been declining with successive arrival cohorts, reflecting sharp declines in fertility in the source country. In contrast to the findings for marriage, however, we find no evidence that the higher fertility of Mexican immigrant women on arrival assimilates towards native levels. Rather, the gap tends to increase still further with time in the United States; this is consistent with the hypothesis that that immigration disrupts or delays immigrant women's fertility causing their relative fertility to rise with residence in the United States and counterbalancing or obscuring whatever assimilation might have otherwise taken place. While the size of the Mexican American-nonhispanic white fertility differential declines across generations, it is not eliminated.

Finally, we separately examined results for married men and women and confirmed our findings based on the full sample, including the dramatic assimilation in labor supply of immigrant women, for this group. This means further that we did not support the family investment model, which has recently been proposed as a model of the immigrant assimilation process in a family context (e.g., Baker and Benjamin 1997). This view holds that, upon arrival, 
immigrant husbands invest in their human capital, while wives work to provide the family with liquidity during the investment period. The model predicts rapid positive assimilation in labor supply for husbands and decreases in wives' labor supply over time relative to the native reference group. On the contrary, we found positive assimilation in labor supply for both immigrant husbands and wives, with dramatically faster assimilation for wives. 


\section{Appendix: Creation of Hourly Earnings Variable}

To analyze hourly earnings, we restrict our sample to wage and salary workers who were employed full time (defined as those with at least 35 usual weekly work hours). Wage and salary workers were defined as those with zero self-employment and zero farm self-employment income in the prior year who were wage and salary workers for their longest job during that year. The CPS reports two wage and salary income variables: one for the main job and one for all other jobs. The main job values were topcoded at $\$ 99,000$ for 1994 and 1995; $\$ 150,000$ for $1996-2002$; and $\$ 200,000$ for 2003 . The values for all other jobs were topcoded at $\$ 99,999$ for 1994 and 1995; $\$ 25,000$ for $1996-2002$; and $\$ 35,000$ for 2003 . For the main job earnings variables, we used the following conventions for topcoding: for 1994-2002, we multiplied the topcoded value by 1.45 , and for 2003 , we forced all topcoded values to equal $\$ 150,000 * 1.45$. For the other jobs variable, we forced all values above $\$ 25,000$ to equal $\$ 25,000$ and then multiplied this by 1.45. We then added the adjusted variables to form annual wage and salary earnings. These were converted to hourly earnings by dividing by (weeks worked times usual hours per week). We then defined hourly earnings in 2000 dollars using the Personal Consumption Expenditures GDP deflator. We kept only those values between $\$ 2$ and $\$ 200$ in 2000 dollars. Results were not sensitive to alternative assumptions about topcoding. 


\section{References}

Angrist, Joshua, "How Do Sex Ratios Affect Marriage and Labor Markets? Evidence from America's Second Generation," Quarterly Journal of Economics 117, no. 3 (August 2002): 997-1038.

Baker, Michael and Dwayne Benjamin. "The Role of the Family in Immigrants' Labor-Market Activity: An Evaluation of Alternative Explanations." American Economic Review 87, no. 4 (September 1997): 705-727.

Baker, Susan Gonzalez, "Mexican-Origin Women in Southwestern Labor Markets," in Irene Browne, ed., Latinas and African American Women at Work (New York: Russell Sage Foundation, 1999), pp. 244-269.

Blank, Rebecca M., It Takes a Nation: A New Agenda for Fighting Poverty (New York and Princeton, NJ: Russell Sage Foundation and Princeton University Press, 1997).

Blau, Francine D., "The Fertility of Immigrant Women: Evidence from High-Fertility Source Countries," in George J. Borjas and Richard B. Freeman, eds., Immigration and the Work Force: Economic Consequences for the United States and Source Areas (Chicago, IL: University of Chicago Press, 1992), pp. 93-133.

Blau, Francine D., and Andrea H. Beller, "Black-White Earnings over the 1970s and 1980s: Gender Differences in Trends," Review of Economics and Statistics 74, no. 2 (May 1992): 276-286.

Blau, Francine D., Marianne A. Ferber, and Anne E. Winkler, The Economics of Women, Men, and Work, $4^{\text {th }}$ ed. (Upper Saddle River, NJ: Prentice Hall, 2002).

Blau, Francine D., Lawrence M. Kahn, Joan Moriarty, and Andre Souza, "The Role of the Family in Immigrants' Labor-Market Activity: An Evaluation of Alternative Explanations: Comment," American Economic Review 93, no. 1 (March 2003): 429447.

Blundell, Richard, and Thomas MaCurdy. "Labor Supply: A Review of Alternative Approaches," in Orley Ashenfelter and David Card, eds., Handbook of labor economics, volume 3A. Amsterdam: Elsevier, 1999, pp. 1559-1695.

Borjas, George J. "Assimilation, Changes in Cohort Quality, and the Earnings of Immigrants." Journal of Labor Economics 3, no. 4 (October 1985): pp. 463-489.

Borjas, George J. "Assimilation and Changes in Cohort Quality Revisited: What Happened to Immigrant Earnings in the 1980s?" Journal of Labor Economics 13, no. 2 (April 1995): pp. 201-245.

Browne, Irene, ed., Latinas and African American Women at Work (New York: Russell Sage Foundation, 1999).

Card, David, “Is the New Immigration Really So Bad?” IZA Discussion Paper No. 1119, April 2004.

Card, David, John DiNardo, and Eugena Estes, "The More Things Change: Immigrants and the Children of Immigrants in the 1940s, the 1970s, and the 1990s," in George J. Borjas, ed., 
Issues in the Economics of Immigration (Chicago: University of Chicago Press, 2000), pp. 227-269.

Chiquiar, Daniel and Gordon Hanson, "International Migration, Self-Selection, and the Distribution of Wages: Evidence from Mexico and the United States, Journal of Political Economy, 113, no. 2 (April 2005): 239-281.

Cobb-Clark, Deborah A. and Vincent Hildebrand, "The Wealth of Mexican Americans," IZA Discussion Paper No. 1150, May 2004.

Corcoran, Mary, Colleen M. Heflin, and Belinda C. Reyes, "The Economic Progress of Mexican and Puerto Rican Women," in Irene Browne, ed., Latinas and African American Women at Work (New York: Russell Sage Foundation, 1999), pp. 105-138.

Duncan, Brian and Stephen Trejo, "Ethnic Identification, Intermarriage, and Unmeasured Progress by Mexican Americans," paper presented at the NBER Conference on Mexican Immigration, Cambridge MA., February 2005.

Duleep, Harriet Orcutt and Daniel J. Dowhan, "Revisiting the Family Investment Model with Longitudinal Data: The Earnings Growth of Immigrant and U.S.-Born Women," IZA Discussion Paper No. 568, September 2002.

Duleep, Harriet Orcutt and Seth Sanders. "The Decision to Work by Married Immigrant Women." Industrial and Labor Relations Review 46, no. 4 (July 1993): 677-690.

Friedberg, Rachel M. "Immigration and the Labor Market.” Ph.D. Dissertation, MIT, 1993.

Heckman, James J., "Sample Selection Bias as a Specification Error," Econometrica 47 (January 1979): 153-162.

Ibarraran, Pablo and Darren Lubotsky, "Mexican Immigration and Self-Selection: New Evidence from the 2000 Mexican Census," paper presented at the NBER Conference on Mexican Immigration, Cambridge MA., February 2005.

International Labour Organization website: //laborsta.ilo.org.

Jaeger, David A., "Reconciling the Old and New Census Bureau Education Questions:

Recommendations for Researchers," Journal of Business \& Economic Statistics 15, no. 3 (July 1997): 300-309.

LaLonde, Robert J., and Robert H. Topel. "The Assimilation of Immigrants in the U.S. Labor Market," in George J. Borjas and Richard B. Freeman, eds., Immigration and the Work Force: Economic Consequences for the United States and Source Areas (Chicago, IL: University of Chicago Press, 1992, pp. 67-92).

Livingston, Gretchen, and Joan R. Kahn, "An American Dream Unfulfilled: The Limited Mobility of Mexican Americans," Social Science Quarterly 83, no. 4 (December 2002): 1003-1012.

Long, James E., "The Effect of Americanization on Earnings: Some Evidence for Women," Journal of Political Economy 88, no. 3 (June 1980): 620-629. 
MacPherson, David A. and James B. Stewart. "The Labor Force Participation and Earnings Profiles of Married Immigrant Females." Quarterly Review of Economics and Business 29, no. 3 (Autumn 1989): 57-72.

Redstone, Ilana and Douglas S. Massey, "Coming to Stay: An Analysis of the U.S. Census Question on Immigrants' Year of Arrival," Demography 41, no. 4 (November 2004): 721-738.

Smith, James P., "Assimilation across the Latino Generations," American Economic Review 93, no. 2 (May 2003): 315-319.

Trejo, Stephen J., "Why Do Mexican Americans Earn Low Wages?" Journal of Political Economy 105, no. 6 (December 1997): 1235-1268.

Trejo, Stephen J., "Intergenerational Progress of Mexican-Origin Workers in the US Labor Market," Journal of Human Resources 38, no. 3 (Summer 2003): 467-489.

US Census Bureau, Industry and Occupation 2000: Crosswalks (web site: (http://www.census.gov/hhes/www/ioindex/crosswalks.html).

US Department of Homeland Security, Office of Immigration Statistics, Yearbook of Immigration Statistics 2002 (Washington, DC: Office of Immigration Statistics 2003). 
Figure 1a: Assimilation of Mexican Americans: Marriage for Men

(1971-80 Arrival Cohort for Immigrants)

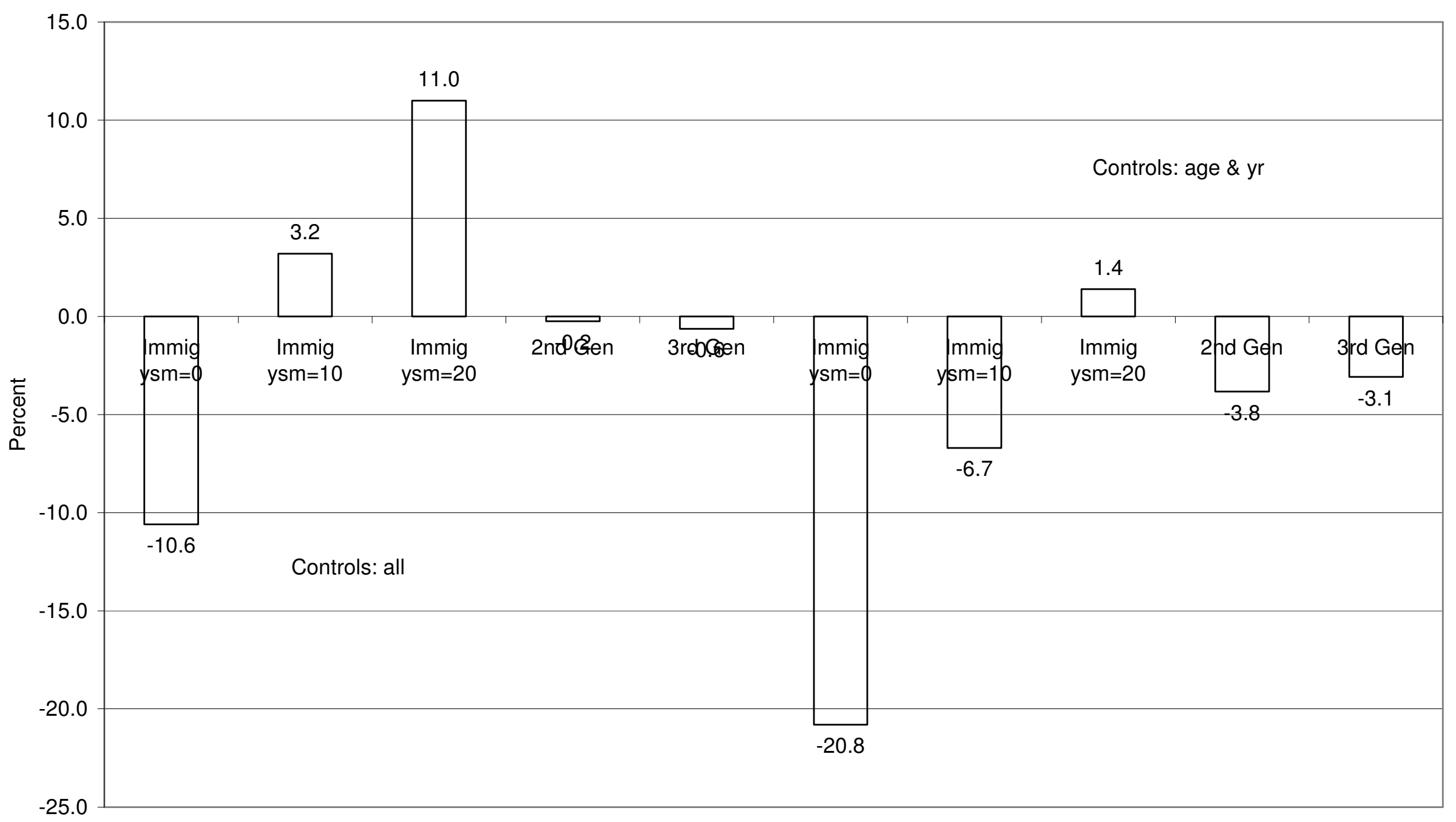

Note: "All" controls include age, yr, educ, region, msa, calif and texas. 
Figure 1b: Assimilation of Mexican Americans: Marriage for Women (1971-80 Arrival Cohort for Immigrants)

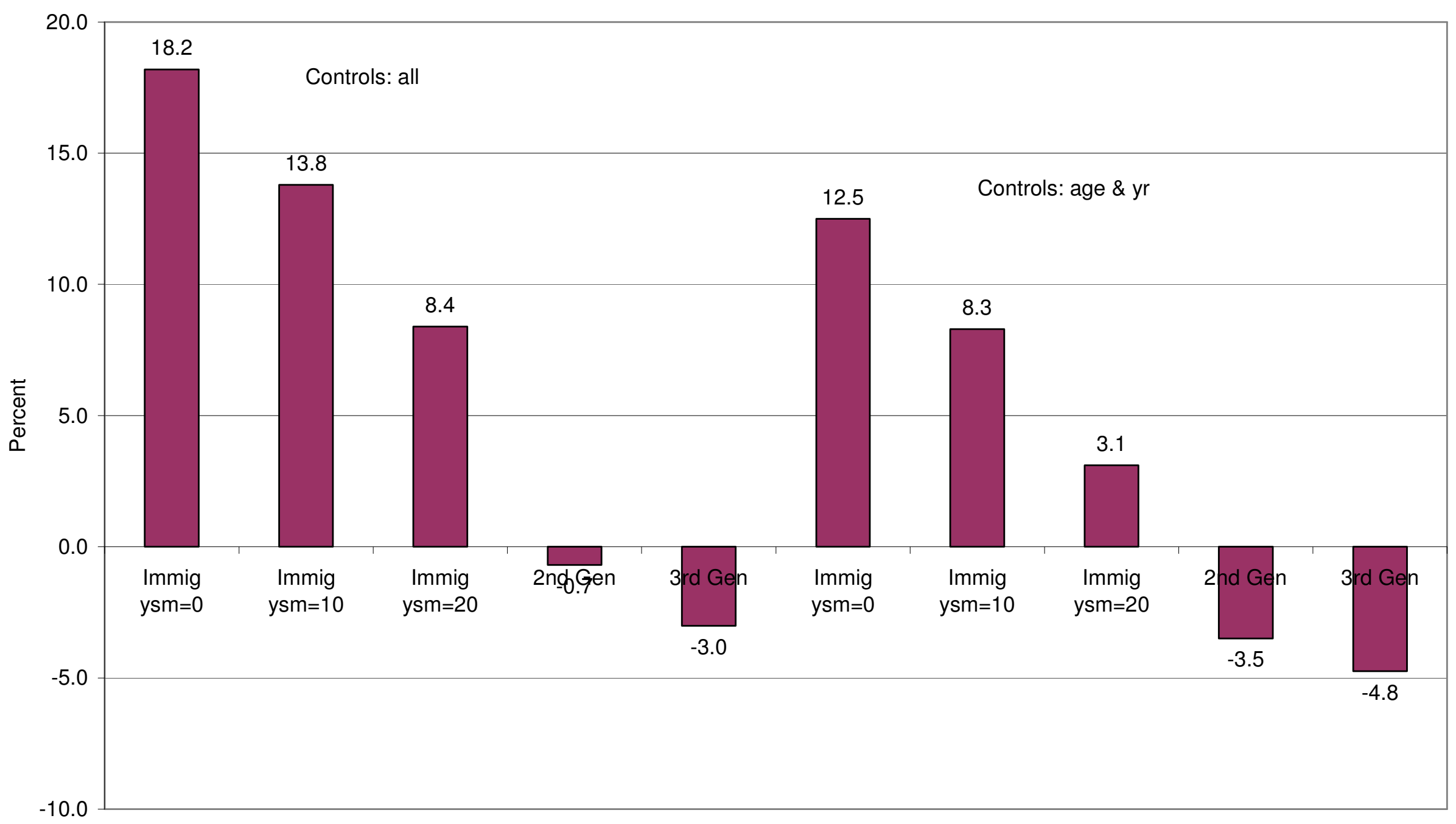

Note: "All" controls include age, yr, educ, region, msa, calif and texas. 
Figure 2: Assimilation of Mexican Americans: Number of Children $<18$ for Women (1971-80 Arrival Cohort for Immigrants)

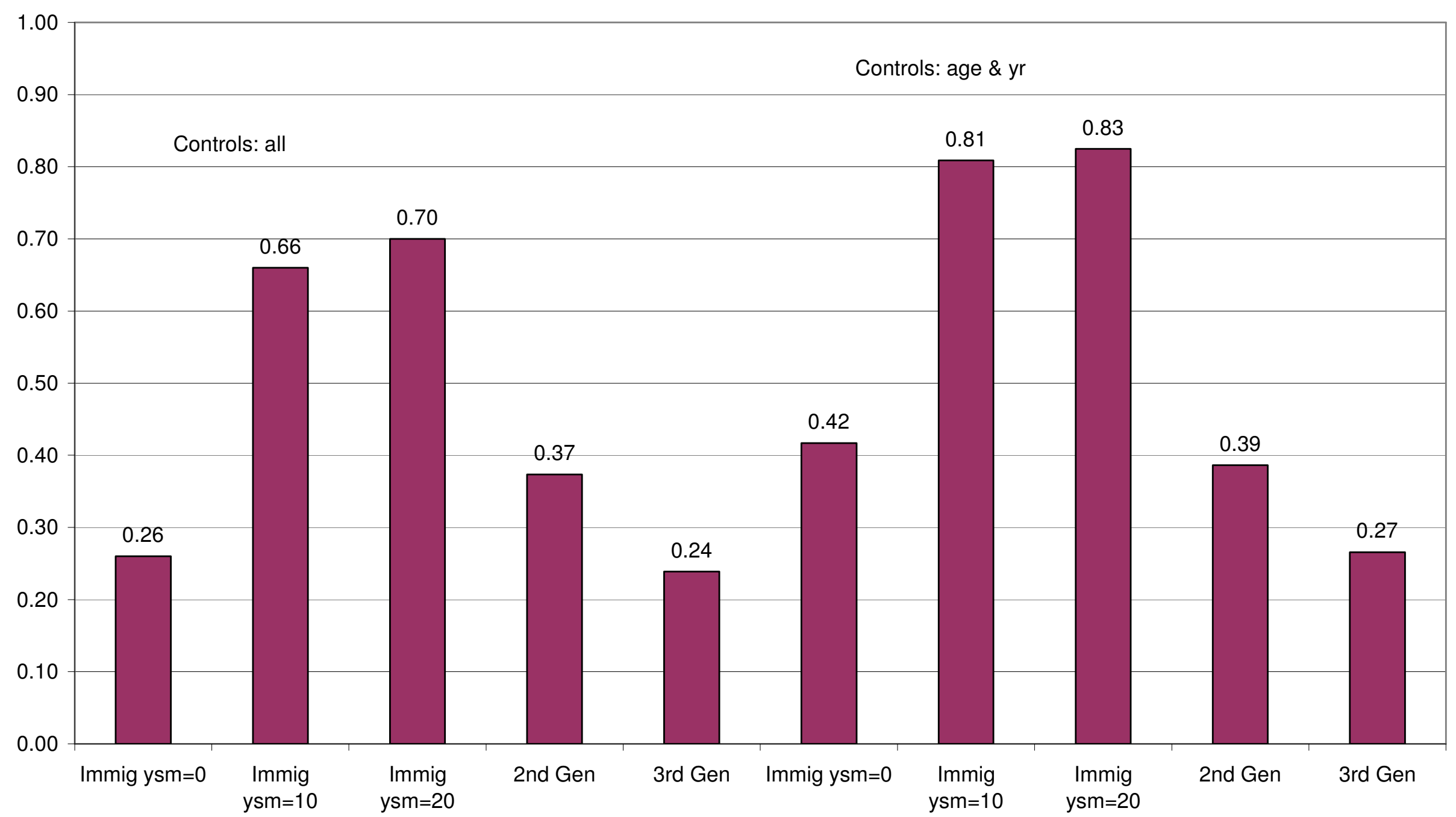

Note: "All" controls include age, yr, educ, region, msa, calif and texas. 
Figure 3a: Assimilation of Mexican Americans: Annual Hours for Men (1971-80 Arrival Cohort for Immigrants)



Note: "All" controls include age, yr, educ, region, msa, calif and texas. 
Figure 3b: Assimilation of Mexican Americans: Annual Hours for Women (1971-80 Arrival Cohort for Immigrants)

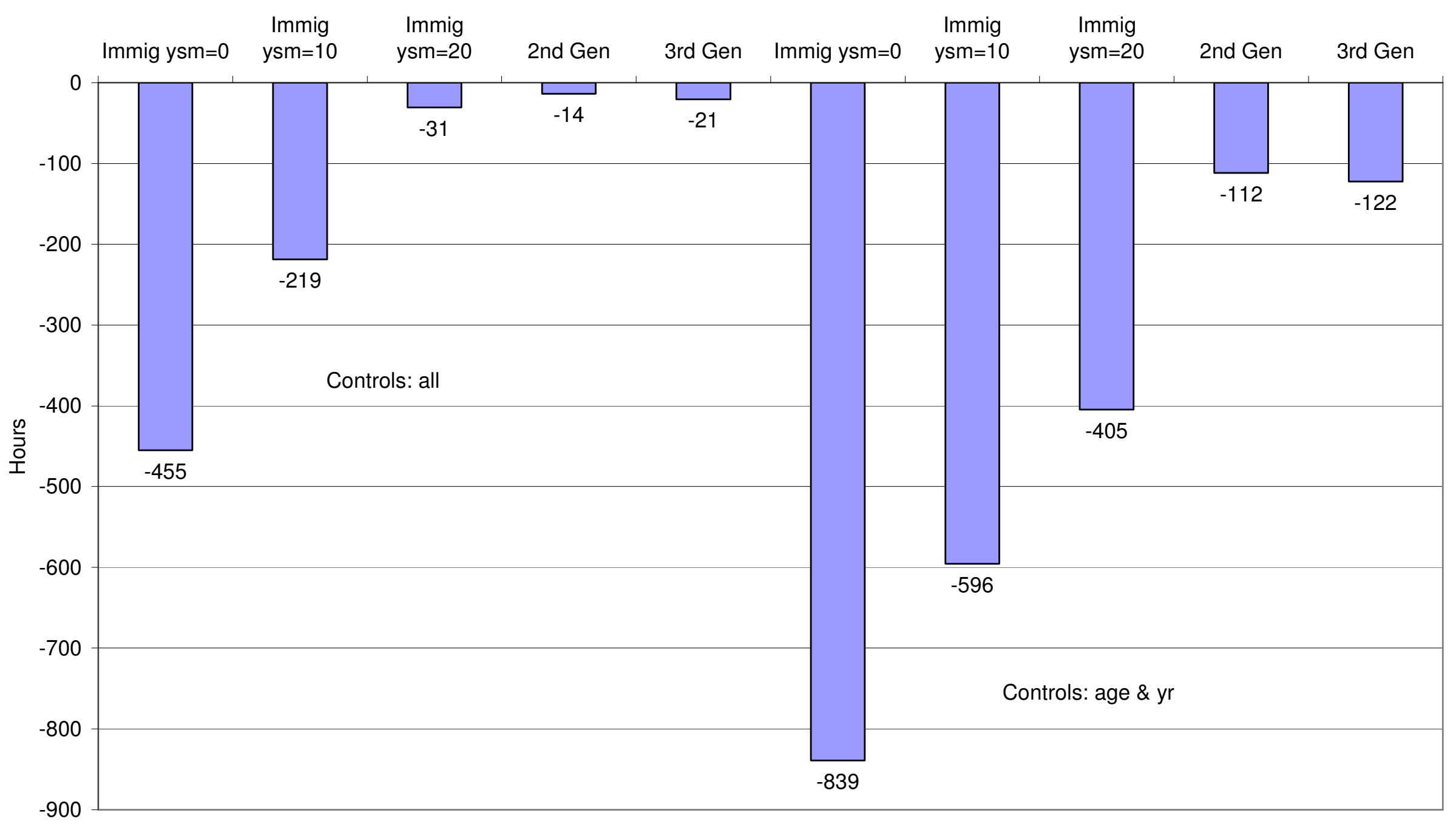

Note: "All" controls include age, yr, educ, region, msa, calif and texas. 
Figure 4a: Assimilation of Mexican Americans: Unemployment Rate for Men (1971-80 Arrival Cohort for Immigrants)

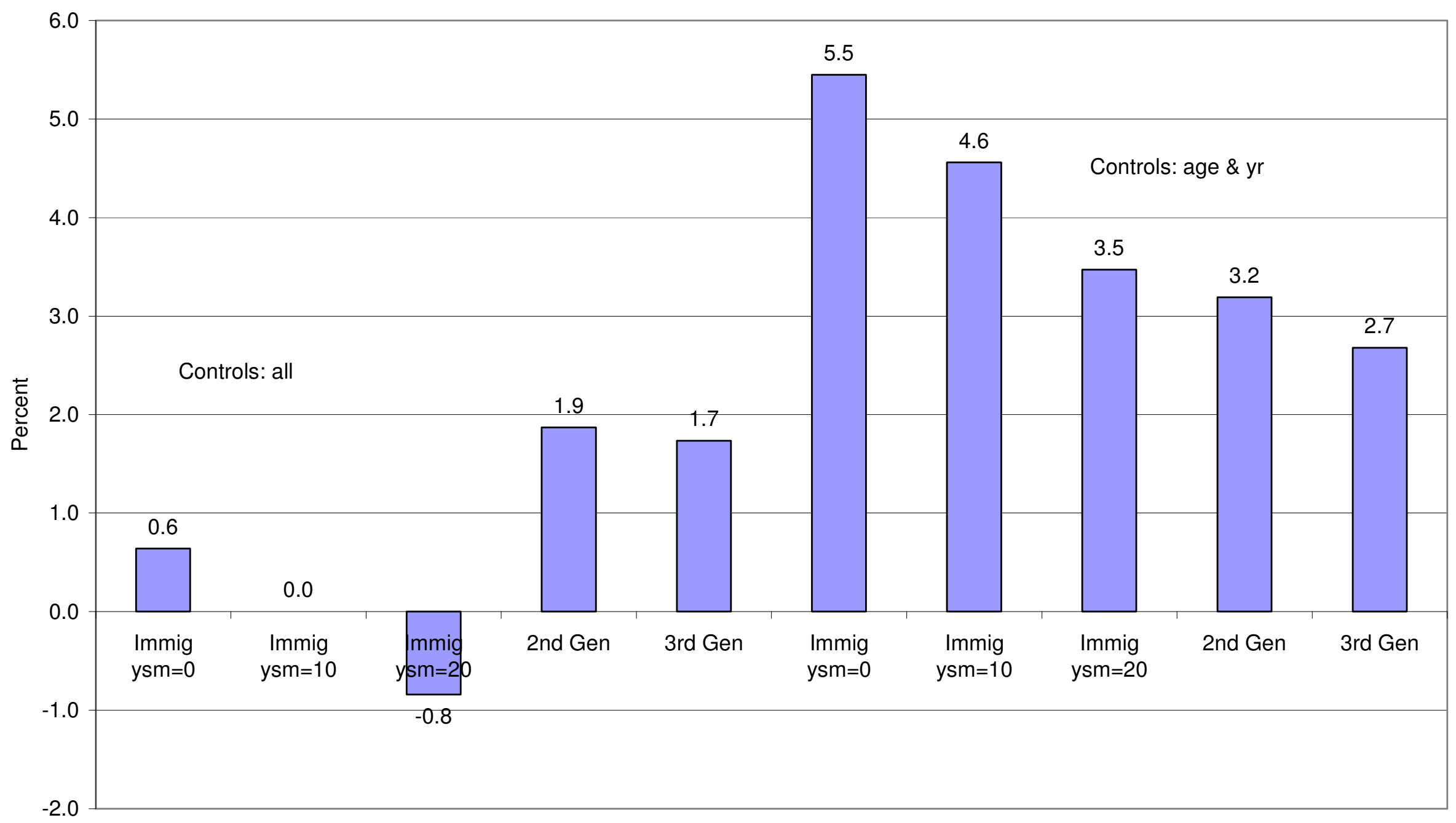

Note: "All" controls include age, yr, educ, region, msa, calif and texas. 
Figure 4b: Assimilation of Mexican Americans: Unemployment Rate for Women (1971-80 Arrival Cohort for Immigrants)



Note: "All" controls include age, yr, educ, region, msa, calif and texas. 
Figure 5a: Assimilation of Mexican Americans: Log Wages for Men (1971-80 Arrival Cohort for Immigrants)

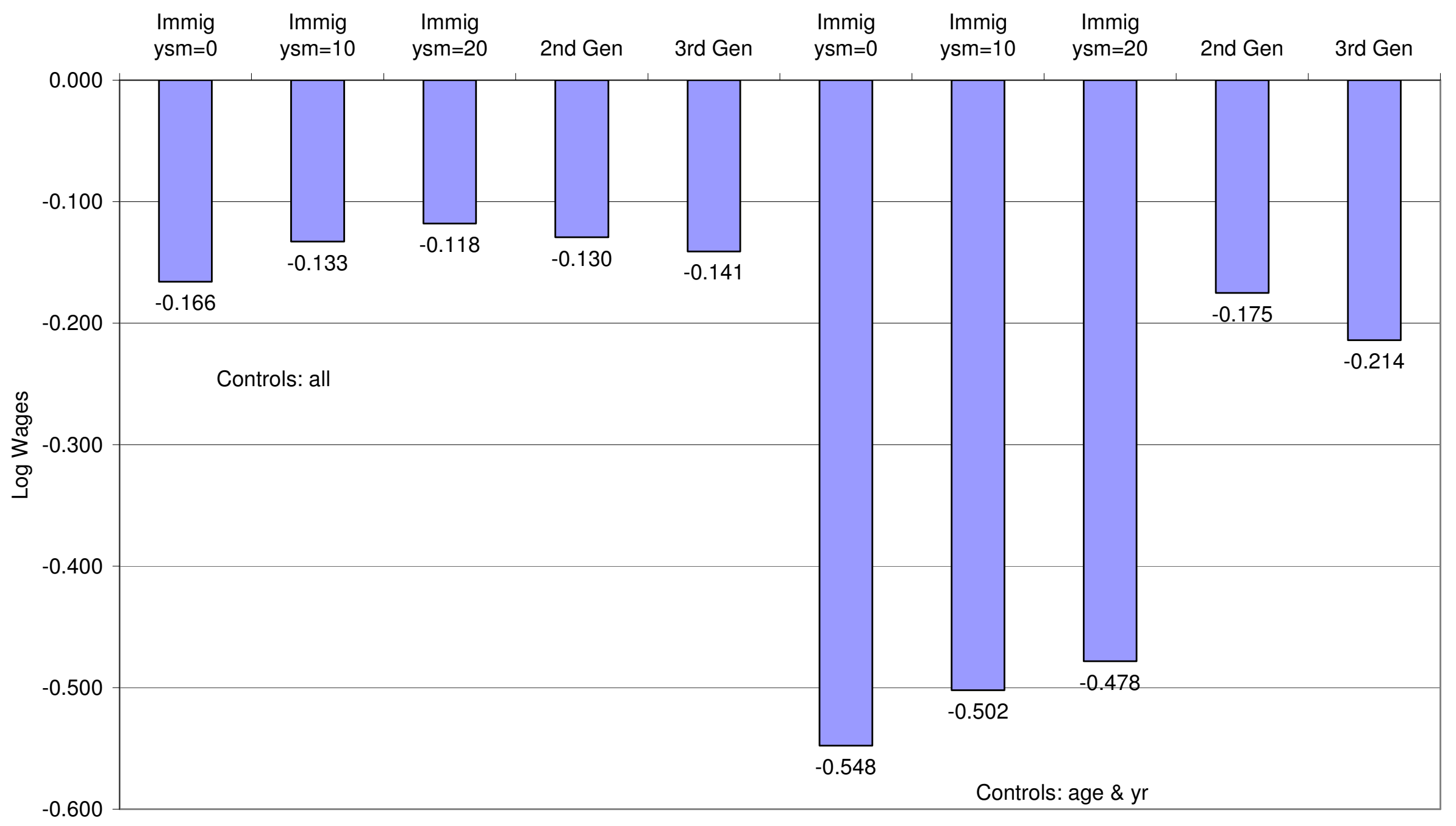

Note: "All" controls include age, yr, educ, region, msa, calif and texas. 
Figure 5b: Assimilation of Mexican Americans: Log Wages for Women (1971-80 Arrival Cohort for Immigrants)

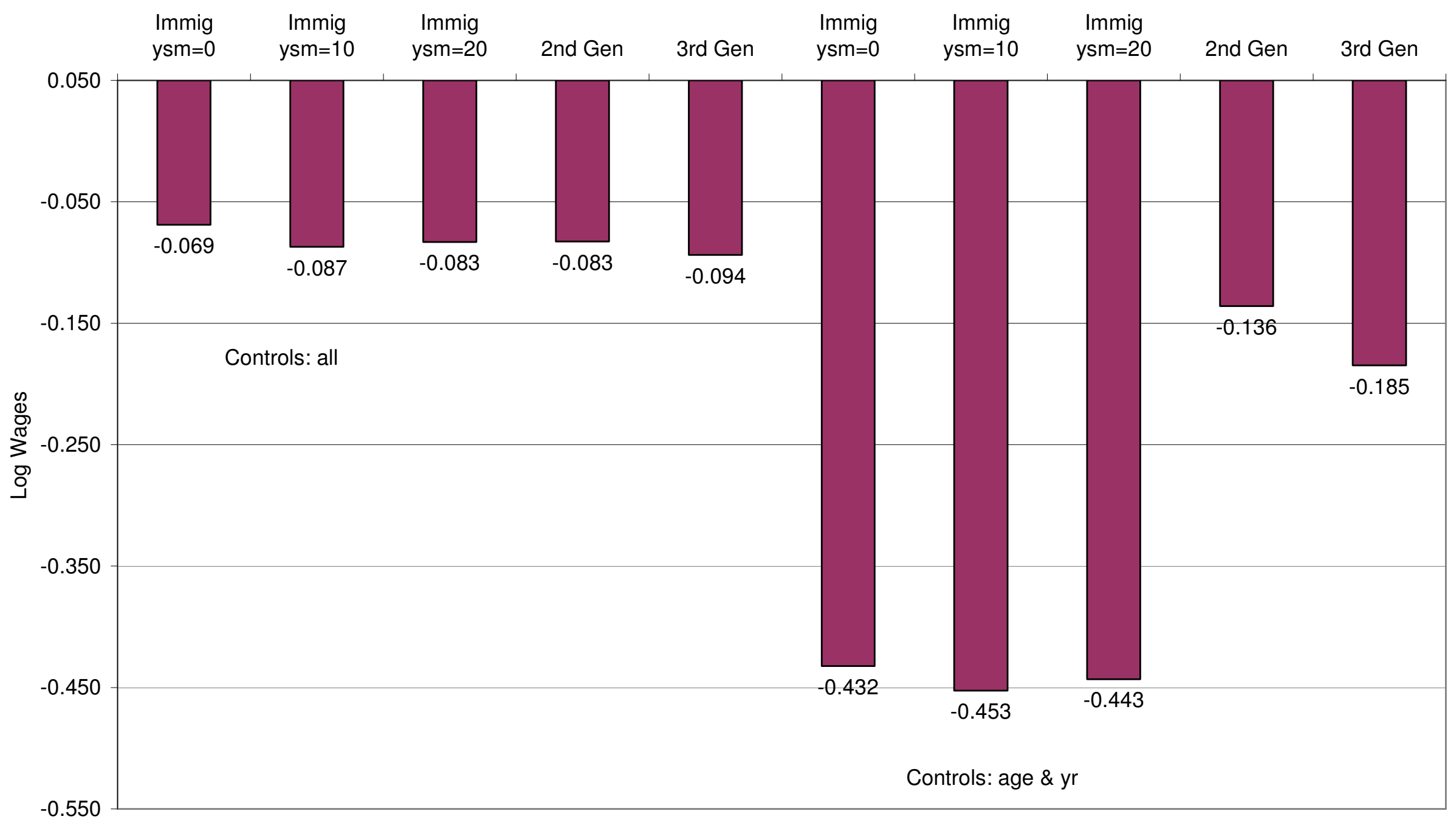

Note: "All" controls include age, yr, educ, region, msa, calif and texas. 
Figure 6a: Assimilation of Mexican Americans: Log Wages for Men (1981-90 Arrival Cohort for Immigrants)

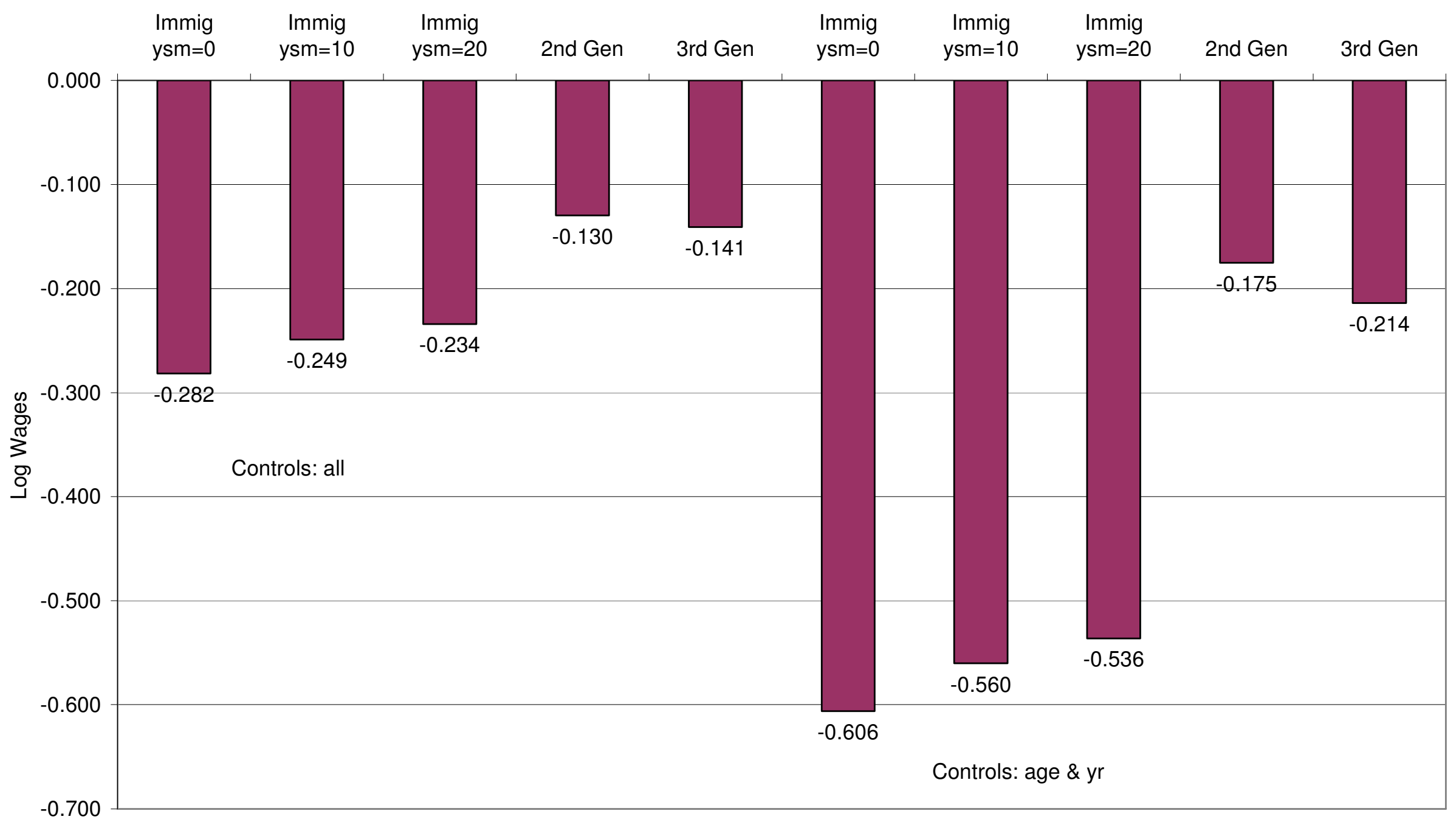

Note: "All" controls include age, yr, educ, region, msa, calif and texas. 
Figure 6b: Assimilation of Mexican Americans: Log Wages for Women (1981-90 Arrival Cohort for Immigrants)

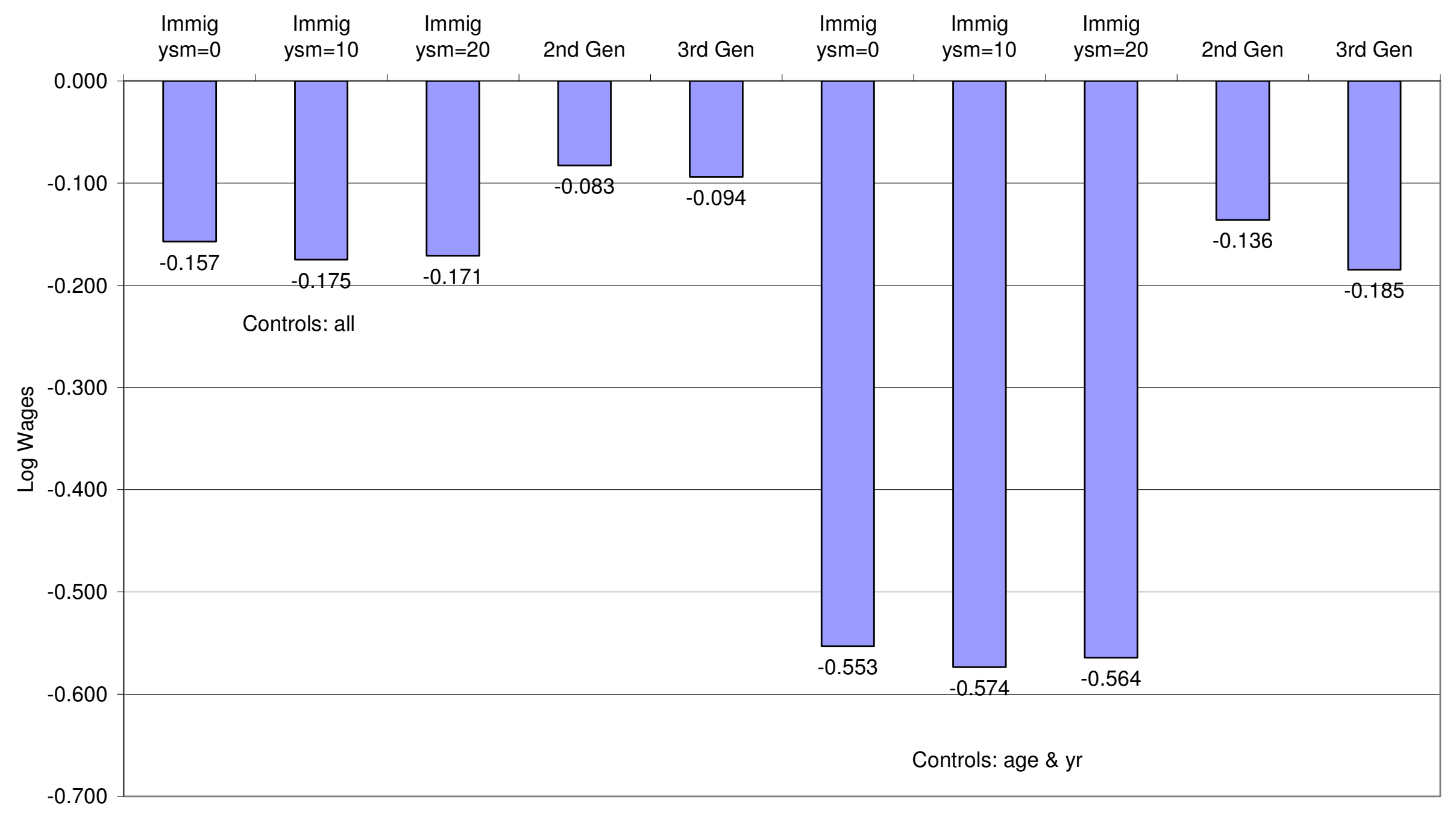

Note: "All" controls include age, yr, educ, region, msa, calif and texas. 
Figure 7: Assimilation Profiles for Married Mexican Immigrant Men and Women Who Immigrated with Mexican Spouse, Annual Work Hours, 1971-80 Arrival Cohort

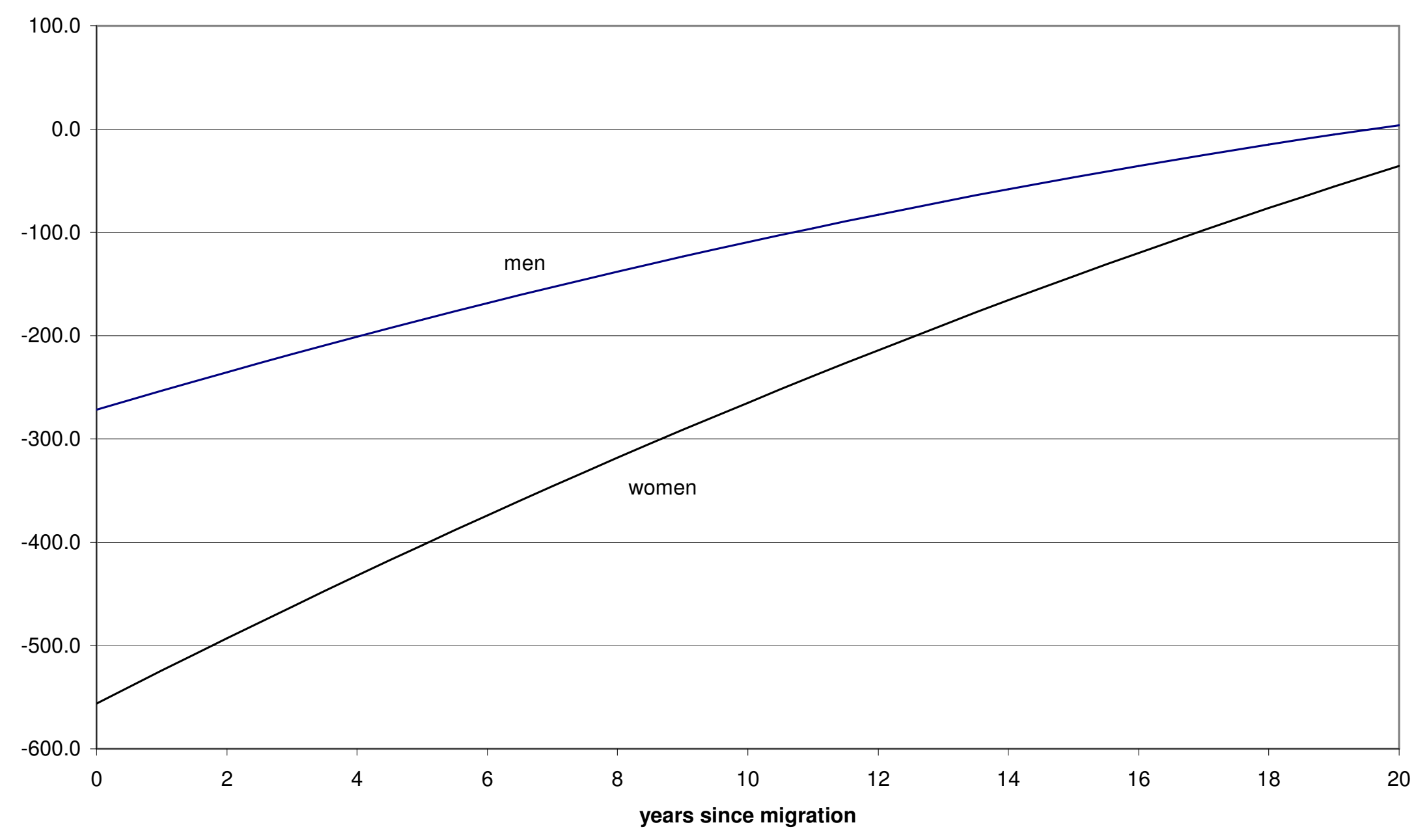


Figure 8: Assimilation Profiles for Married Mexican Men and Women Who Immigrated with Mexican Spouse, Log Hourly Earnings, Fulltime Wage and Salary Workers, 1971-80 and 198190 Arrival Cohorts




Figure 9: Assimilation Profile for Married Mexican Immigrant Women Who Immigrated with Mexican Spouse, Number of Children Under 18, 1971-80 Arrival Cohort

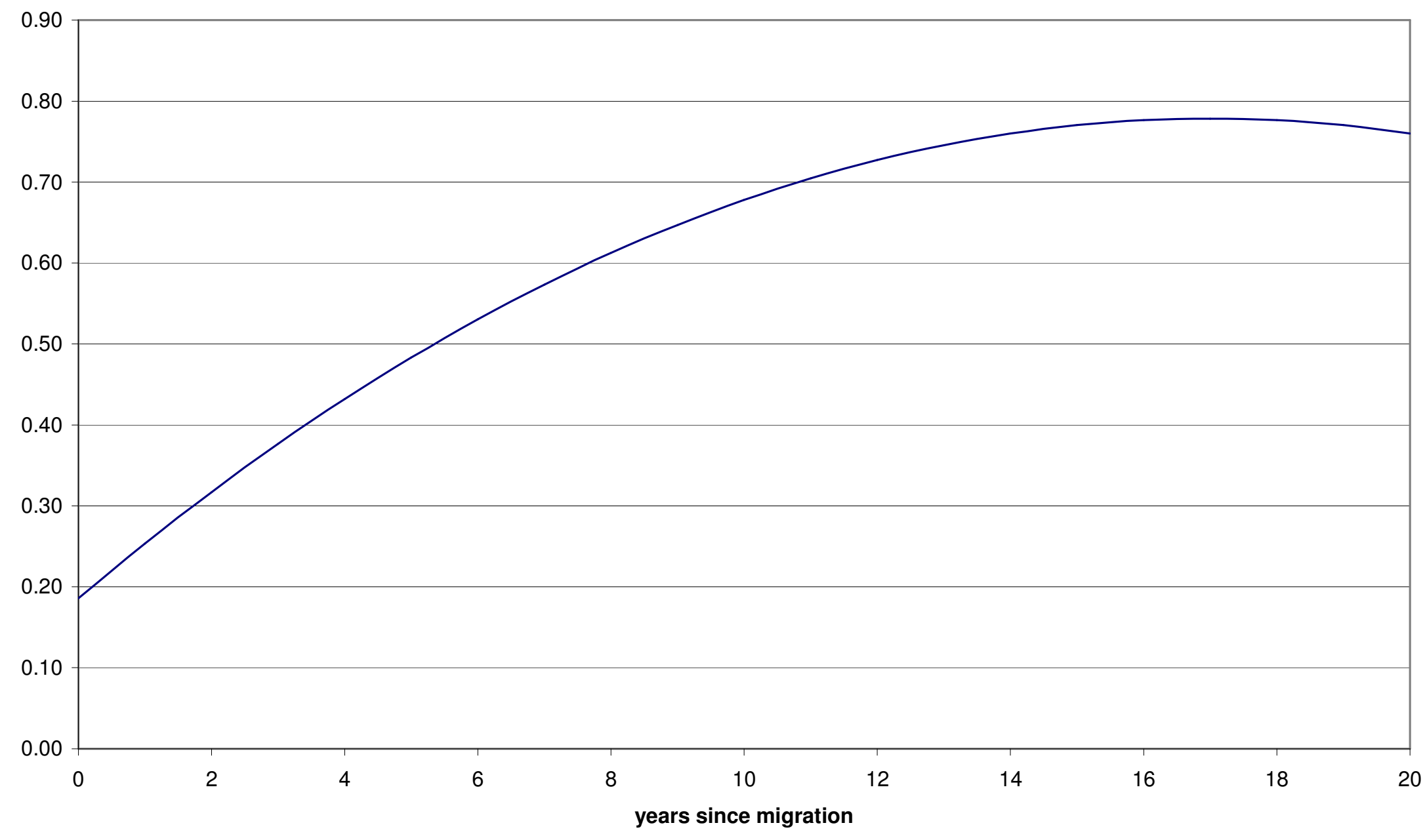


Table 1: Age and Year-Corrected Levels of Demographic, Human Capital and Wage Outcomes for Mexican-Americans and Native Nonhispanic Whites (Third Generation), 1994-2003

\begin{tabular}{|c|c|c|c|c|c|c|}
\hline \multirow{5}{*}{$\begin{array}{l}\text { Native, Nonhispanic Whites } \\
\text { Mexican-Americans }\end{array}$} & \multicolumn{2}{|c|}{ Education } & \multicolumn{2}{|c|}{$\begin{array}{l}\text { Married, Spouse } \\
\text { Present }\end{array}$} & \multicolumn{2}{|c|}{$\begin{array}{c}\text { Number.of Children } \\
<18 y r s\end{array}$} \\
\hline & Level & se & Level & se & Level & se \\
\hline & \multicolumn{6}{|c|}{ Men } \\
\hline & 13.723 & 0.015 & 0.687 & 0.003 & -- & -- \\
\hline & & & & & & \\
\hline All Immigrants & 9.094 & 0.024 & 0.704 & 0.004 & -- & -- \\
\hline Adult Immigrants & 8.254 & 0.028 & 0.663 & 0.005 & -- & -- \\
\hline Second Generation & 12.651 & 0.035 & 0.650 & 0.006 & -- & -- \\
\hline \multirow[t]{2}{*}{ Third Generation } & 12.533 & 0.030 & 0.657 & 0.005 & -- & -- \\
\hline & \multicolumn{6}{|c|}{ Women } \\
\hline Native, Nonhispanic Whites & 13.856 & 0.014 & 0.705 & 0.003 & 1.458 & 0.007 \\
\hline \multicolumn{7}{|l|}{ Mexican-Americans } \\
\hline All Immigrants & 9.162 & 0.023 & 0.776 & 0.004 & 2.159 & 0.012 \\
\hline Adult Immigrants & 8.280 & 0.027 & 0.758 & 0.005 & 2.138 & 0.014 \\
\hline Second Generation & 12.670 & 0.031 & 0.670 & 0.006 & 1.845 & 0.016 \\
\hline \multirow[t]{4}{*}{ Third Generation } & 12.498 & 0.026 & 0.657 & 0.005 & 1.724 & 0.013 \\
\hline & \multicolumn{2}{|c|}{ Currently Employed } & \multicolumn{2}{|c|}{ Annual Work Hours } & \multicolumn{2}{|c|}{ Currently in LF } \\
\hline & Level & se & Level & se & Level & se \\
\hline & \multicolumn{6}{|c|}{ Men } \\
\hline Native, Nonhispanic Whites & 0.869 & 0.002 & 2096.81 & 5.17 & 0.909 & 0.002 \\
\hline \multicolumn{7}{|l|}{ Mexican-Americans } \\
\hline All Immigrants & 0.872 & 0.004 & 1963.80 & 8.03 & 0.933 & 0.003 \\
\hline Adult Immigrants & 0.863 & 0.004 & 1886.38 & 9.78 & 0.930 & 0.004 \\
\hline Second Generation & 0.818 & 0.005 & 1947.97 & 11.77 & 0.878 & 0.005 \\
\hline \multirow{2}{*}{ Third Generation } & 0.818 & 0.004 & 1919.15 & 10.10 & 0.877 & 0.004 \\
\hline & \multicolumn{6}{|c|}{ Women } \\
\hline Native, Nonhispanic Whites & 0.764 & 0.003 & 1463.48 & 5.50 & 0.792 & 0.003 \\
\hline Mexican-Americans & & & & & & \\
\hline All Immigrants & 0.480 & 0.004 & 935.22 & 9.08 & 0.536 & 0.004 \\
\hline Adult Immigrants & 0.444 & 0.005 & 838.42 & 10.91 & 0.503 & 0.005 \\
\hline Second Generation & 0.672 & 0.006 & 1353.53 & 12.38 & 0.725 & 0.006 \\
\hline \multirow[t]{4}{*}{ Third Generation } & 0.687 & 0.005 & 1342.21 & 10.51 & 0.730 & 0.005 \\
\hline & \multicolumn{2}{|c|}{ Unemployed | in LF } & \multicolumn{2}{|c|}{ Log Wages (FT) } & & \\
\hline & Level & se & Level & se & & \\
\hline & \multicolumn{4}{|c|}{ Men } & & \\
\hline Native, Nonhispanic Whites & 0.047 & 0.001 & 2.985 & 0.005 & & \\
\hline \multicolumn{7}{|l|}{ Mexican-Americans } \\
\hline All Immigrants & 0.070 & 0.002 & 2.468 & 0.007 & & \\
\hline Adult Immigrants & 0.077 & 0.003 & 2.354 & 0.008 & & \\
\hline Second Generation & 0.079 & 0.003 & 2.810 & 0.011 & & \\
\hline \multirow[t]{2}{*}{ Third Generation } & 0.074 & 0.003 & 2.771 & 0.009 & & \\
\hline & & & nen & & & \\
\hline Native, Nonhispanic Whites & 0.039 & 0.001 & 2.717 & 0.005 & & \\
\hline Mexican-Americans & & & & & & \\
\hline All Immigrants & 0.114 & 0.003 & 2.213 & 0.010 & & \\
\hline Adult Immigrants & 0.125 & 0.003 & 2.079 & 0.012 & & \\
\hline Second Generation & 0.085 & 0.003 & 2.582 & 0.012 & & \\
\hline Third Generation & 0.065 & 0.003 & 2.533 & 0.010 & & \\
\hline
\end{tabular}




\section{Notes to Table 1}

Based on pooled equations with a quartic in age, year dummies, and dummies for each Mexican-American generation. Results for adult immigrants are based on regression with Native Nonhispanic whites, and the three Mexican-American generations pooled, where the immigrant generation includes only those who migrated at age 18 or older. Sample for number of children under age 18 is restricted to respondents who are age 50 or less; sample for log wages is full-time wage and salary workers. Predictions assume the mean age: 39 years and year=2003. Native, Nonhispanic whites are limited to third generation. 
Table 2: Selected Regression Results for Demographic and Labor Market Outcomes

\begin{tabular}{|c|c|c|c|c|c|c|c|c|}
\hline \multirow[t]{3}{*}{ Dependent Variable } & \multicolumn{4}{|c|}{ Marriage } & \multicolumn{4}{|c|}{ No. Children $<18$} \\
\hline & \multicolumn{2}{|c|}{ Men } & \multicolumn{2}{|c|}{ Women } & \multicolumn{2}{|c|}{ Women } & \multicolumn{2}{|c|}{ Women } \\
\hline & coef & se & coef & se & coef & se & coef & se \\
\hline immig: pre 1961 arrival & -0.083 & 0.051 & 0.238 & 0.056 & 1.178 & 0.190 & 0.954 & 0.183 \\
\hline immig: $1961-70$ arrival & -0.090 & 0.032 & 0.216 & 0.036 & 0.473 & 0.100 & 0.329 & 0.097 \\
\hline immig: $1971-80$ arrival & -0.106 & 0.024 & 0.182 & 0.027 & 0.260 & 0.069 & 0.120 & 0.067 \\
\hline immig: $1981-90$ arrival & -0.024 & 0.017 & 0.169 & 0.020 & 0.331 & 0.052 & 0.201 & 0.050 \\
\hline immig: $1991-96$ arrival & -0.014 & 0.011 & 0.232 & 0.013 & 0.250 & 0.035 & 0.086 & 0.034 \\
\hline immig: $1997-2002$ arrival & -0.079 & 0.010 & 0.154 & 0.012 & 0.045 & 0.030 & -0.065 & 0.029 \\
\hline years since mig (ysm) & 0.017 & 0.002 & -0.004 & 0.002 & 0.058 & 0.006 & 0.062 & 0.005 \\
\hline ysm squared (/100) & -0.028 & 0.004 & -0.005 & 0.005 & -0.184 & 0.017 & -0.184 & 0.016 \\
\hline second gen Mexican-American & -0.002 & 0.006 & -0.007 & 0.006 & 0.373 & 0.015 & 0.371 & 0.014 \\
\hline third gen Mexican-American & -0.006 & 0.005 & -0.030 & 0.005 & 0.239 & 0.012 & 0.258 & 0.012 \\
\hline control for marital status? & --- & --- & --- & --- & $n$ & & ye & \\
\hline \multirow[t]{3}{*}{ Dependent Variable } & \multicolumn{4}{|c|}{ Annual Work Hours } & \multicolumn{4}{|c|}{ Unemployment | in Labor Force } \\
\hline & \multicolumn{2}{|c|}{ Men } & \multicolumn{2}{|c|}{ Women } & \multicolumn{2}{|c|}{ Men } & \multicolumn{2}{|c|}{ Women } \\
\hline & coef & se & coef & se & coef & se & coef & se \\
\hline immig: pre 1961 arrival & -187.57 & 99.45 & -642.74 & 112.38 & 0.015 & 0.029 & 0.155 & 0.035 \\
\hline immig: $1961-70$ arrival & -73.37 & 63.03 & -653.59 & 73.35 & 0.041 & 0.018 & 0.143 & 0.023 \\
\hline immig: $1971-80$ arrival & 44.15 & 47.43 & -454.92 & 55.59 & 0.006 & 0.013 & 0.103 & 0.018 \\
\hline immig: $1981-90$ arrival & 105.85 & 33.70 & -463.57 & 39.68 & -0.005 & 0.009 & 0.099 & 0.014 \\
\hline immig: $1991-96$ arrival & 172.72 & 22.20 & -479.20 & 25.83 & -0.019 & 0.006 & 0.090 & 0.009 \\
\hline immig: $1997-2002$ arrival & 217.77 & 19.32 & -417.03 & 23.89 & -0.023 & 0.005 & 0.060 & 0.008 \\
\hline years since mig (ysm) & 4.85 & 3.26 & 26.02 & 3.80 & -0.001 & 0.001 & -0.004 & 0.001 \\
\hline ysm squared $(/ 100)$ & 3.55 & 7.93 & -23.87 & 9.13 & -0.001 & 0.002 & 0.002 & 0.003 \\
\hline second gen Mexican-American & -57.09 & 10.90 & -13.66 & 11.46 & 0.019 & 0.003 & 0.034 & 0.003 \\
\hline third gen Mexican-American & -105.02 & 9.24 & -20.50 & 9.63 & 0.017 & 0.003 & 0.015 & 0.003 \\
\hline \multirow[t]{3}{*}{ Dependent Variable } & \multicolumn{4}{|c|}{ Log Wages (FT) } & & & & \\
\hline & \multicolumn{2}{|c|}{ Men } & \multicolumn{2}{|c|}{ Women } & & & & \\
\hline & coef & se & coef & se & & & & \\
\hline immig: pre 1961 arrival & -0.150 & 0.080 & -0.075 & 0.111 & & & & \\
\hline immig: $1961-70$ arrival & -0.162 & 0.048 & -0.113 & 0.073 & & & & \\
\hline immig: $1971-80$ arrival & -0.166 & 0.036 & -0.069 & 0.059 & & & & \\
\hline immig: $1981-90$ arrival & -0.282 & 0.026 & -0.157 & 0.045 & & & & \\
\hline immig: $1991-96$ arrival & -0.246 & 0.018 & -0.191 & 0.032 & & & & \\
\hline immig: $1997-2002$ arrival & -0.209 & 0.015 & -0.182 & 0.028 & & & & \\
\hline years since mig (ysm) & 0.004 & 0.003 & -0.003 & 0.004 & & & & \\
\hline ysm squared $(/ 100)$ & -0.009 & 0.007 & 0.011 & 0.011 & & & & \\
\hline second gen Mexican-American & -0.130 & 0.010 & -0.083 & 0.010 & & & & \\
\hline third gen Mexican-American & -0.141 & 0.008 & -0.094 & 0.008 & & & & \\
\hline
\end{tabular}

Other controls include: a quartic in age, years of schooling, 8 Census region dummies, an MSA dummy, dummies for California and Texas, and year dummies. 


\section{Table 3: Occupational and Industrial Segregation Indexes by Gender}

\begin{tabular}{lcc}
\hline & Industry & Occupation \\
\cline { 2 - 3 } White Nonhispanic Natives with Native Parents & 0.337 & 0.360 \\
Mexican Immigrants & 0.336 & 0.394 \\
Mexican Immigrants, in US at Least 10 Yrs & 0.345 & 0.393 \\
Mexican Immigrants: migrated age 18 or higher & 0.335 & 0.391 \\
Mexican Immigrants: migrated age 18 or higher and in & 0.346 & 0.397 \\
US at Least 10 Yrs & & \\
Second Generation Mexican Americans & 0.356 & 0.416 \\
Third Generation Mexican Americans & 0.347 & 0.446 \\
\hline
\end{tabular}


Table 4: Occupational and Industrial Segregation Indexes Relative to White Nonhispanic Natives with Native Parents

\begin{tabular}{lcccc}
\hline & \multicolumn{2}{c}{ Industry } & \multicolumn{2}{c}{ Occupation } \\
\cline { 2 - 5 } & Men & Women & Men & Women \\
\cline { 2 - 5 } Mexican Immigrants & 0.264 & 0.320 & 0.411 & 0.478 \\
Mexican Immigrants, in US at Least 10 Yrs & 0.218 & 0.270 & 0.378 & 0.435 \\
Mexican Immigrants: migrated age 18 or higher & 0.280 & 0.373 & 0.447 & 0.580 \\
Mexican Immigrants: migrated age 18 or higher and in & 0.233 & 0.349 & 0.420 & 0.571 \\
US at Least 10 Yrs & & & & \\
Second Generation Mexican Americans & 0.100 & 0.070 & 0.178 & 0.149 \\
Third Generation Mexican Americans & 0.079 & 0.062 & 0.185 & 0.122 \\
\hline
\end{tabular}




\section{Table 5: Ethnicity and Nativity of Marriage Patterns, Married Mexican-American Women and Men}

\begin{tabular}{|c|c|c|c|c|}
\hline \multicolumn{5}{|l|}{ A. Married Mexican-American Women } \\
\hline Wife's Generation & Mexican Immigrants & $\begin{array}{l}\text { Second Generation } \\
\text { Mexican Americans }\end{array}$ & $\begin{array}{l}\text { Third Generation } \\
\text { Mexican Americans }\end{array}$ & $\begin{array}{l}\text { Mexican American: All } \\
\text { Generations }\end{array}$ \\
\hline Mexican American Immigrants & 0.835 & 0.057 & 0.028 & 0.920 \\
\hline Second Generation Mexican Americans & 0.321 & 0.247 & 0.172 & 0.740 \\
\hline Third Generation Mexican Americans & 0.098 & 0.122 & 0.479 & 0.699 \\
\hline All Mexican-American Wives & 0.540 & 0.106 & 0.181 & 0.827 \\
\hline \multicolumn{5}{|l|}{ B. Married Mexican-American Men } \\
\hline & \multicolumn{4}{|c|}{ Fraction of Wives Who Were: } \\
\hline Husband's Generation & Mexican Immigrants & $\begin{array}{l}\text { Second Generation } \\
\text { Mexican Americans }\end{array}$ & $\begin{array}{l}\text { Third Generation } \\
\text { Mexican Americans }\end{array}$ & $\begin{array}{l}\text { Mexican American: All } \\
\text { Generations }\end{array}$ \\
\hline Mexican American Immigrants & 0.792 & 0.079 & 0.045 & 0.916 \\
\hline Second Generation Mexican Americans & 0.219 & 0.256 & 0.226 & 0.701 \\
\hline Third Generation Mexican Americans & 0.060 & 0.099 & 0.505 & 0.664 \\
\hline All Mexican-American Husbands & 0.512 & 0.109 & 0.196 & 0.817 \\
\hline
\end{tabular}




\begin{tabular}{|c|c|c|c|c|c|c|}
\hline \multicolumn{7}{|l|}{ A. Married Women } \\
\hline & \multicolumn{2}{|c|}{ No. Children $<18$ yrs } & \multicolumn{2}{|c|}{ Annual Work Hours } & \multicolumn{2}{|c|}{ Log Wages (FT) } \\
\hline & coef & se & coef & se & coef & se \\
\hline education & -0.026 & 0.001 & 68.49 & 1.00 & 0.097 & 0.001 \\
\hline spouse education & 0.0062 & 0.0006 & -8.98 & 0.43 & 0.0031 & 0.0003 \\
\hline immig: pre 1961 arrival & 0.476 & 0.250 & -835.70 & 172.85 & 0.025 & 0.160 \\
\hline immig: $1961-70$ arrival & -0.079 & 0.155 & -926.21 & 124.09 & -0.061 & 0.122 \\
\hline immig: $1971-80$ arrival & -0.084 & 0.120 & -777.13 & 101.22 & -0.114 & 0.106 \\
\hline immig: $1981-90$ arrival & 0.026 & 0.095 & -733.33 & 77.97 & -0.187 & 0.085 \\
\hline immig: $1991-96$ arrival & -0.041 & 0.073 & -729.16 & 59.08 & -0.217 & 0.065 \\
\hline immig: $1997-2002$ arrival & -0.165 & 0.070 & -725.28 & 57.72 & -0.202 & 0.061 \\
\hline spouse immig: pre 1961 arrival & 0.604 & 0.208 & -38.58 & 155.68 & 0.045 & 0.146 \\
\hline spouse immig: $1961-70$ arrival & 0.298 & 0.147 & 89.50 & 123.06 & 0.058 & 0.117 \\
\hline spouse immig: $1971-80$ arrival & 0.270 & 0.124 & 220.94 & 103.63 & 0.116 & 0.101 \\
\hline spouse immig: 1981-90 arrival & 0.139 & 0.098 & 135.84 & 79.77 & 0.020 & 0.079 \\
\hline spouse immig: 1991-96 arrival & 0.106 & 0.077 & 161.19 & 63.00 & 0.055 & 0.061 \\
\hline spouse immig: 1997-2002 arrival & 0.090 & 0.077 & 149.58 & 63.68 & 0.077 & 0.062 \\
\hline years since migration (ysm) & 0.050 & 0.008 & 43.41 & 6.27 & 0.007 & 0.008 \\
\hline ysm squared $(/ 100)$ & -0.141 & 0.023 & -54.75 & 14.07 & -0.018 & 0.017 \\
\hline spouse years since migration (sysm) & 0.019 & 0.008 & -11.17 & 6.01 & -0.008 & 0.006 \\
\hline sysm squared (/100) & -0.064 & 0.017 & 23.68 & 11.15 & 0.019 & 0.012 \\
\hline Mex Imm, Spouse 2nd gen Mexican & 0.157 & 0.072 & -53.79 & 56.94 & 0.016 & 0.052 \\
\hline Mex imm, Spouse 3rd gen Mexican & -0.012 & 0.089 & -40.70 & 70.65 & -0.030 & 0.060 \\
\hline 2nd gen Mexican, Spouse Mex Immig & 0.219 & 0.063 & -70.35 & 51.43 & -0.124 & 0.041 \\
\hline $\begin{array}{l}\text { Both 2nd gen Mexican } \\
\text { 2nd gen Mexican, Spouse 3rd gen }\end{array}$ & 0.322 & 0.050 & -8.49 & 36.69 & -0.067 & 0.029 \\
\hline Mexican & 0.340 & 0.055 & 87.72 & 43.75 & -0.083 & 0.032 \\
\hline $\begin{array}{l}\text { 3rd gen Mexican, Spouse Mex Imm } \\
\text { 3rd gen Mexican, Spouse 2nd gen }\end{array}$ & 0.304 & 0.072 & -127.66 & 58.73 & -0.111 & 0.046 \\
\hline Mexican & 0.252 & 0.052 & 99.78 & 38.80 & -0.095 & 0.028 \\
\hline Both 3rd gen Mexican & 0.336 & 0.026 & -3.48 & 20.26 & -0.124 & 0.016 \\
\hline
\end{tabular}


Table 6: Selected Results for Demographic and Employment Outcomes, Married Couple Sample (ctd)

\begin{tabular}{|c|c|c|c|c|}
\hline \multirow[t]{3}{*}{ B. Married Men } & \multirow{2}{*}{\multicolumn{2}{|c|}{ Log Wages (FT) }} & \multirow{2}{*}{\multicolumn{2}{|c|}{ Annual Work Hours }} \\
\hline & & & & \\
\hline & coef & se & coef & se \\
\hline education & 0.076 & 0.001 & 49.97 & 0.77 \\
\hline spouse education & 0.0024 & 0.0003 & 2.37 & 0.34 \\
\hline immig: pre 1961 arrival & -0.222 & 0.103 & -448.36 & 133.57 \\
\hline immig: $1961-70$ arrival & -0.282 & 0.075 & -294.15 & 103.05 \\
\hline immig: $1971-80$ arrival & -0.263 & 0.063 & -141.68 & 86.72 \\
\hline immig: $1981-90$ arrival & -0.326 & 0.049 & -74.30 & 66.73 \\
\hline immig: $1991-96$ arrival & -0.327 & 0.038 & -40.52 & 51.68 \\
\hline immig: $1997-2002$ arrival & -0.241 & 0.039 & -103.89 & 53.14 \\
\hline spouse immig: pre 1961 arrival & -0.004 & 0.117 & 124.85 & 147.37 \\
\hline spouse immig: $1961-70$ arrival & -0.008 & 0.078 & -33.47 & 105.57 \\
\hline spouse immig: $1971-80$ arrival & -0.027 & 0.062 & -129.98 & 86.06 \\
\hline spouse immig: $1981-90$ arrival & -0.099 & 0.048 & -127.36 & 65.58 \\
\hline spouse immig: 1991-96 arrival & -0.060 & 0.036 & -49.92 & 49.06 \\
\hline spouse immig: $1997-2002$ arrival & -0.115 & 0.035 & -61.23 & 48.47 \\
\hline years since migration (ysm) & 0.018 & 0.004 & 11.65 & 5.24 \\
\hline ysm squared (/100) & -0.033 & 0.009 & 1.08 & 10.38 \\
\hline spouse years since migration (sysm) & -0.005 & 0.004 & 7.04 & 5.21 \\
\hline sysm squared $(/ 100)$ & 0.006 & 0.009 & -25.66 & 11.28 \\
\hline Mex Imm, Spouse 2nd gen Mexican & -0.003 & 0.031 & -59.82 & 42.86 \\
\hline Mex imm, Spouse 3rd gen Mexican & -0.053 & 0.037 & -140.93 & 50.28 \\
\hline 2nd gen Mexican, Spouse Mex Immig & -0.107 & 0.035 & 27.05 & 47.90 \\
\hline Both 2nd gen Mexican & -0.146 & 0.024 & -94.26 & 31.69 \\
\hline 2nd gen Mexican, Spouse 3rd gen & & & & \\
\hline Mexican & -0.189 & 0.024 & -72.14 & 33.45 \\
\hline $\begin{array}{l}\text { 3rd gen Mexican, Spouse Mex Imm } \\
\text { 3rd gen Mexican, Spouse 2nd gen }\end{array}$ & -0.158 & 0.042 & -67.38 & 57.66 \\
\hline Mexican & -0.208 & 0.027 & -171.15 & 36.93 \\
\hline Both 3rd gen Mexican & -0.185 & 0.013 & -145.14 & 17.22 \\
\hline
\end{tabular}

Note: controls include age, spouse age, region, msa, calif, texas, and dummies for spouse white nonhispanic, and spouse other non-Mexican origin. Female sample includes white nonhispanic third generation women married to white nonhispanic third generation men and married women of Mexican origin; male sample includes white nonhispanic third generation men married to white nonhispanic third generation women and married men of Mexican origin. 
Table A1: Sample Sizes for Basic Regression Analyses

\begin{tabular}{lrr}
\hline Group & Men & Women \\
\hline $\begin{array}{l}\text { Third Generation White, } \\
\text { Nonhispanics }\end{array}$ & 286531 & 300008 \\
Mexican Americans & & \\
Immigrants & 20733 & 18858 \\
Second Generation & 7456 & 8214 \\
$\quad$ Third Generation & 11348 & 12664 \\
\hline
\end{tabular}


Table A2: Selected Regression Results for Demographic and Labor Market Outcomes, Controlling only for Age and Year

\begin{tabular}{|c|c|c|c|c|c|c|c|c|}
\hline \multirow[t]{3}{*}{ Dependent Variable } & \multicolumn{4}{|c|}{ Marriage } & \multirow{2}{*}{\multicolumn{2}{|c|}{$\begin{array}{c}\begin{array}{c}\text { No. Children } \\
<18\end{array} \\
\text { Women } \\
\end{array}$}} & & \\
\hline & \multicolumn{2}{|c|}{ Men } & \multicolumn{2}{|c|}{ Women } & & & & \\
\hline & coef & se & coef & se & coef & se & & \\
\hline immig: pre 1961 arrival & -0.171 & 0.051 & 0.189 & 0.056 & 1.319 & 0.190 & & \\
\hline immig: $1961-70$ arrival & -0.191 & 0.033 & 0.158 & 0.036 & 0.598 & 0.100 & & \\
\hline immig: $1971-80$ arrival & -0.208 & 0.024 & 0.125 & 0.027 & 0.417 & 0.069 & & \\
\hline immig: $1981-90$ arrival & -0.117 & 0.017 & 0.116 & 0.020 & 0.477 & 0.052 & & \\
\hline imig: $1991-96$ arrival & -0.095 & 0.011 & 0.186 & 0.013 & 0.396 & 0.034 & & \\
\hline immig: $1997-2002$ arrival & -0.157 & 0.010 & 0.115 & 0.012 & 0.184 & 0.030 & & \\
\hline years since mig (ysm) & 0.017 & 0.002 & -0.004 & 0.002 & 0.058 & 0.006 & & \\
\hline ysm squared (/100) & -0.028 & 0.004 & -0.005 & 0.005 & -0.188 & 0.017 & & \\
\hline 2nd gen Mexican-American & -0.038 & 0.005 & -0.035 & 0.005 & 0.386 & 0.014 & & \\
\hline 3rd gen Mexican-American & -0.031 & 0.005 & -0.048 & 0.005 & 0.266 & 0.012 & & \\
\hline \multirow[t]{3}{*}{ Dependent Variable } & \multicolumn{4}{|c|}{ Annual Work Hours } & \multicolumn{4}{|c|}{ Unemployment | in Labor Force } \\
\hline & \multicolumn{2}{|c|}{ Men } & \multicolumn{2}{|c|}{ Women } & \multicolumn{2}{|c|}{ Men } & \multicolumn{2}{|c|}{ Women } \\
\hline & coef & se & coef & se & coef & se & coef & se \\
\hline immig: pre 1961 arrival & -482.3 & 101.2 & -949.3 & 114.4 & 0.052 & 0.029 & 0.191 & 0.036 \\
\hline immig: $1961-70$ arrival & -438.0 & 64.1 & -1000.9 & 74.6 & 0.086 & 0.018 & 0.179 & 0.023 \\
\hline immig: $1971-80$ arrival & -340.3 & 48.1 & -839.0 & 56.4 & 0.055 & 0.013 & 0.143 & 0.018 \\
\hline immig: $1981-90$ arrival & -234.4 & 34.1 & -835.0 & 40.2 & 0.038 & 0.009 & 0.139 & 0.014 \\
\hline imig: $1991-96$ arrival & -130.8 & 22.4 & -839.2 & 26.0 & 0.019 & 0.006 & 0.127 & 0.008 \\
\hline immig: $1997-2002$ arrival & -82.8 & 19.4 & -751.5 & 24.0 & 0.012 & 0.005 & 0.092 & 0.008 \\
\hline years since mig (ysm) & 6.6 & 3.3 & 26.9 & 3.9 & -0.001 & 0.001 & -0.004 & 0.001 \\
\hline ysm squared $(/ 100)$ & 1.2 & 8.1 & -25.9 & 9.3 & -0.001 & 0.002 & 0.001 & 0.003 \\
\hline 2nd gen Mexican-American & -148.2 & 10.7 & -111.8 & 11.3 & 0.032 & 0.003 & 0.047 & 0.003 \\
\hline 3rd gen Mexican-American & -177.2 & 9.0 & -122.2 & 9.3 & 0.027 & 0.003 & 0.026 & 0.002 \\
\hline \multirow[t]{3}{*}{ Dependent Variable } & \multicolumn{4}{|c|}{ Log Wages (FT) } & & & & \\
\hline & \multicolumn{2}{|c|}{ Men } & \multicolumn{2}{|c|}{ Women } & & & & \\
\hline & coef & se & coef & se & & & & \\
\hline immig: pre 1961 arrival & -0.402 & 0.087 & -0.335 & 0.126 & & & & \\
\hline immig: $1961-70$ arrival & -0.459 & 0.052 & -0.394 & 0.084 & & & & \\
\hline immig: $1971-80$ arrival & -0.548 & 0.039 & -0.432 & 0.068 & & & & \\
\hline immig: $1981-90$ arrival & -0.606 & 0.028 & -0.553 & 0.051 & & & & \\
\hline imig: $1991-96$ arrival & -0.573 & 0.019 & -0.560 & 0.036 & & & & \\
\hline immig: $1997-2002$ arrival & -0.541 & 0.016 & -0.563 & 0.032 & & & & \\
\hline years since mig (ysm) & 0.006 & 0.003 & -0.004 & 0.005 & & & & \\
\hline ysm squared $(/ 100)$ & -0.011 & 0.007 & 0.015 & 0.012 & & & & \\
\hline 2nd gen Mexican-American & -0.175 & 0.010 & -0.136 & 0.011 & & & & \\
\hline 3rd gen Mexican-American & -0.214 & 0.008 & -0.185 & 0.009 & & & & \\
\hline
\end{tabular}


Table A3: Means of Explanatory Variables by Group

\begin{tabular}{|c|c|c|c|c|c|c|c|c|}
\hline & \multirow{2}{*}{\multicolumn{2}{|c|}{ Nonhispanic Whites }} & \multicolumn{6}{|c|}{ Mexican Americans } \\
\hline & & & \multicolumn{2}{|c|}{ Immigrants } & \multicolumn{2}{|c|}{ Second Generation } & \multicolumn{2}{|c|}{ Third Generation } \\
\hline & Men & Women & Men & Women & Men & Women & Men & Women \\
\hline age & 38.90 & 39.18 & 34.20 & 35.21 & 31.58 & 31.82 & 34.14 & 34.85 \\
\hline age squared & 1687.5 & 1710.7 & 1298.6 & 1379.9 & 1190.9 & 1207.0 & 1324.7 & 1372.4 \\
\hline $\mathrm{age}^{3}$ & 79370.5 & 80928.9 & 54159.1 & 59350.8 & 52102.3 & 52987.5 & 56966.0 & 59629.1 \\
\hline $\mathrm{age}^{4}$ & 3959187 & 4058389 & 2444970 & 2755546 & 2535968 & 2581753 & 2647491 & 2792618 \\
\hline education & 13.240 & 13.220 & 8.670 & 8.667 & 11.718 & 11.683 & 11.913 & 11.847 \\
\hline immig: pre 1961 arrival & 0 & 0 & 0.020 & 0.023 & 0 & 0 & 0 & 0 \\
\hline immig: $1961-70$ arrival & 0 & 0 & 0.060 & 0.068 & 0 & 0 & 0 & 0 \\
\hline immig: $1971-80$ arrival & 0 & 0 & 0.215 & 0.218 & 0 & 0 & 0 & 0 \\
\hline immig: $1981-90$ arrival & 0 & 0 & 0.351 & 0.323 & 0 & 0 & 0 & 0 \\
\hline imig: $1991-96$ arrival & 0 & 0 & 0.218 & 0.248 & 0 & 0 & 0 & 0 \\
\hline immig: $1997-2002$ arrival & 0 & 0 & 0.135 & 0.120 & 0 & 0 & 0 & 0 \\
\hline years since mig (ysm) & 0 & 0 & 14.34 & 14.69 & 0 & 0 & 0 & 0 \\
\hline ysm squared $(/ 100)$ & 0 & 0 & 3.1 & 3.2 & 0 & 0 & 0 & 0 \\
\hline year $=1994$ & 0.102 & 0.102 & 0.085 & 0.086 & 0.093 & 0.087 & 0.089 & 0.085 \\
\hline year $=1995$ & 0.102 & 0.102 & 0.094 & 0.090 & 0.093 & 0.094 & 0.084 & 0.085 \\
\hline year $=1996$ & 0.102 & 0.101 & 0.092 & 0.093 & 0.097 & 0.093 & 0.089 & 0.089 \\
\hline year $=1997$ & 0.100 & 0.100 & 0.099 & 0.093 & 0.099 & 0.095 & 0.092 & 0.089 \\
\hline year $=1998$ & 0.100 & 0.100 & 0.099 & 0.097 & 0.105 & 0.096 & 0.099 & 0.096 \\
\hline year $=1999$ & 0.100 & 0.101 & 0.095 & 0.097 & 0.093 & 0.099 & 0.110 & 0.109 \\
\hline year $=2000$ & 0.100 & 0.100 & 0.100 & 0.103 & 0.090 & 0.102 & 0.108 & 0.109 \\
\hline year $=2001$ & 0.099 & 0.099 & 0.102 & 0.106 & 0.097 & 0.107 & 0.102 & 0.112 \\
\hline year $=2002$ & 0.098 & 0.098 & 0.117 & 0.116 & 0.115 & 0.111 & 0.112 & 0.109 \\
\hline year $=2003$ (omitted category) & 0.097 & 0.097 & 0.118 & 0.120 & 0.118 & 0.115 & 0.117 & 0.116 \\
\hline lives in metropolitan area & 0.762 & 0.762 & 0.905 & 0.912 & 0.900 & 0.901 & 0.856 & 0.861 \\
\hline lives in california & 0.079 & 0.078 & 0.460 & 0.493 & 0.456 & 0.450 & 0.286 & 0.294 \\
\hline lives in texas & 0.057 & 0.057 & 0.200 & 0.213 & 0.284 & 0.302 & 0.421 & 0.431 \\
\hline New England Census Division & 0.055 & 0.055 & 0.002 & 0.001 & 0.001 & 0.001 & 0.002 & 0.002 \\
\hline Middle Atlantic Census Division & 0.133 & 0.134 & 0.032 & 0.023 & 0.007 & 0.007 & 0.006 & 0.005 \\
\hline East North Central Census Division & 0.190 & 0.190 & 0.081 & 0.071 & 0.073 & 0.069 & 0.053 & 0.050 \\
\hline West North Central Census Division & 0.092 & 0.090 & 0.018 & 0.015 & 0.015 & 0.015 & 0.022 & 0.018 \\
\hline South Atlantic Census Division & 0.173 & 0.173 & 0.058 & 0.038 & 0.022 & 0.023 & 0.025 & 0.023 \\
\hline East South Central Census Division & 0.071 & 0.073 & 0.006 & 0.004 & 0.002 & 0.002 & 0.006 & 0.005 \\
\hline West South Central Census Division & 0.099 & 0.099 & 0.207 & 0.218 & 0.290 & 0.309 & 0.431 & 0.441 \\
\hline Mountain Census Division & 0.065 & 0.064 & 0.108 & 0.112 & 0.116 & 0.109 & 0.156 & 0.145 \\
\hline $\begin{array}{l}\text { Pacific Census Division (omitted } \\
\text { category) }\end{array}$ & 0.122 & 0.121 & 0.488 & 0.516 & 0.474 & 0.465 & 0.300 & 0.311 \\
\hline Sample Size & 286531 & 300008 & 20733 & 18858 & 7456 & 8214 & 11348 & 12664 \\
\hline
\end{tabular}


Table A4: Selected Regression Results for Demographic and Labor Market Outcomes (Adult Immigrants Only)

\begin{tabular}{|c|c|c|c|c|c|c|c|c|}
\hline \multirow[t]{3}{*}{ Dependent Variable } & \multicolumn{4}{|c|}{ Marriage } & \multicolumn{4}{|c|}{ No. Children $<18$} \\
\hline & \multicolumn{2}{|c|}{ Men } & \multicolumn{2}{|c|}{ Women } & \multicolumn{2}{|c|}{ Women } & \multicolumn{2}{|c|}{ Women } \\
\hline & coef & se & coef & se & coef & se & coef & se \\
\hline immig: pre 1961 arrival & 0.036 & 0.085 & 0.146 & 0.088 & -- & -- & -- & -- \\
\hline immig: $1961-70$ arrival & -0.054 & 0.046 & 0.184 & 0.051 & 0.706 & 0.199 & 0.583 & 0.192 \\
\hline immig: $1971-80$ arrival & -0.100 & 0.032 & 0.138 & 0.035 & 0.314 & 0.090 & 0.197 & 0.087 \\
\hline immig: $1981-90$ arrival & -0.077 & 0.023 & 0.100 & 0.025 & 0.172 & 0.066 & 0.082 & 0.063 \\
\hline imig: 1991-96 arrival & -0.052 & 0.015 & 0.191 & 0.016 & 0.150 & 0.044 & 0.011 & 0.043 \\
\hline immig: $1997-2002$ arrival & -0.116 & 0.012 & 0.132 & 0.014 & -0.005 & 0.036 & -0.103 & 0.034 \\
\hline years since mig (ysm) & 0.022 & 0.003 & -0.002 & 0.003 & 0.088 & 0.008 & 0.091 & 0.008 \\
\hline ysm squared $(/ 100)$ & -0.046 & 0.008 & -0.006 & 0.008 & -0.344 & 0.031 & -0.346 & 0.030 \\
\hline second gen Mexican-American & -0.0002 & 0.006 & -0.006 & 0.006 & 0.377 & 0.015 & 0.373 & 0.014 \\
\hline third gen Mexican-American & -0.005 & 0.005 & -0.030 & 0.005 & 0.241 & 0.012 & 0.260 & 0.012 \\
\hline control for marital status? & ---- & ---- & ---- & ---- & & & $y$ & \\
\hline \multirow[t]{3}{*}{ Dependent Variable } & \multicolumn{4}{|c|}{ Annual Work Hours } & \multicolumn{4}{|c|}{ Unemployment | in Labor Force } \\
\hline & \multicolumn{2}{|c|}{ Men } & \multicolumn{2}{|c|}{ Women } & \multicolumn{2}{|c|}{ Men } & \multicolumn{2}{|c|}{ Women } \\
\hline & coef & se & coef & se & coef & se & coef & se \\
\hline immig: pre 1961 arrival & -79.6 & 165.0 & -378.5 & 178.4 & 0.014 & 0.055 & 0.151 & 0.060 \\
\hline immig: $1961-70$ arrival & -135.2 & 90.4 & -692.9 & 102.8 & 0.085 & 0.025 & 0.054 & 0.032 \\
\hline immig: $1971-80$ arrival & -29.1 & 62.4 & -453.2 & 70.9 & 0.033 & 0.017 & 0.084 & 0.023 \\
\hline immig: $1981-90$ arrival & -20.7 & 45.2 & -471.9 & 51.4 & 0.018 & 0.012 & 0.087 & 0.018 \\
\hline imig: 1991-96 arrival & 27.1 & 29.2 & -551.5 & 33.1 & -0.009 & 0.008 & 0.091 & 0.012 \\
\hline immig: $1997-2002$ arrival & 96.4 & 22.8 & -486.1 & 27.7 & -0.019 & 0.006 & 0.055 & 0.009 \\
\hline years since mig (ysm) & 17.7 & 5.0 & 29.8 & 5.6 & -0.002 & 0.001 & -0.004 & 0.002 \\
\hline ysm squared $(/ 100)$ & -22.2 & 15.2 & -27.7 & 16.9 & 0.001 & 0.004 & 0.004 & 0.006 \\
\hline second gen Mexican-American & -54.2 & 10.9 & -12.4 & 11.5 & 0.019 & 0.003 & 0.034 & 0.003 \\
\hline third gen Mexican-American & -103.5 & 9.3 & -20.6 & 9.7 & 0.017 & 0.003 & 0.015 & 0.003 \\
\hline \multirow[t]{3}{*}{ Dependent Variable } & \multicolumn{4}{|c|}{ Log Wages (FT) } & & & & \\
\hline & \multicolumn{2}{|c|}{ Men } & \multicolumn{2}{|c|}{ Women } & & & & \\
\hline & coef & se & coef & se & & & & \\
\hline immig: pre 1961 arrival & -0.079 & 0.178 & -0.185 & 0.223 & & & & \\
\hline immig: $1961-70$ arrival & -0.191 & 0.071 & -0.051 & 0.102 & & & & \\
\hline immig: $1971-80$ arrival & -0.172 & 0.046 & -0.007 & 0.076 & & & & \\
\hline immig: $1981-90$ arrival & -0.341 & 0.034 & -0.170 & 0.059 & & & & \\
\hline imig: $1991-96$ arrival & -0.303 & 0.023 & -0.220 & 0.042 & & & & \\
\hline immig: $1997-2002$ arrival & -0.247 & 0.018 & -0.243 & 0.032 & & & & \\
\hline years since mig (ysm) & 0.002 & 0.004 & -0.004 & 0.007 & & & & \\
\hline ysm squared $(/ 100)$ & 0.002 & 0.012 & 0.013 & 0.019 & & & & \\
\hline second gen Mexican-American & -0.127 & 0.010 & -0.082 & 0.010 & & & & \\
\hline third gen Mexican-American & -0.138 & 0.008 & -0.093 & 0.008 & & & & \\
\hline
\end{tabular}

Other controls include: a quartic in age, years of schooling, 8 Census region dummies, an MSA dummy, dummies for California and Texas, and year dummies. 
Table A5: Industrial and Occupational Distribution by Gender

\begin{tabular}{|c|c|c|c|c|c|c|c|c|c|c|c|c|c|c|}
\hline \multirow[t]{2}{*}{ Industry } & \multicolumn{2}{|c|}{$\begin{array}{c}\text { White, } \\
\text { Nonhispanic } \\
\text { Natives with } \\
\text { Native Parents }\end{array}$} & \multicolumn{2}{|c|}{$\begin{array}{c}\text { Mexican } \\
\text { Immigrants }\end{array}$} & \multicolumn{2}{|c|}{$\begin{array}{c}\text { Mexican } \\
\text { Immigrants, in } \\
\text { US at Least } 10 \\
\text { Years }\end{array}$} & \multicolumn{2}{|c|}{$\begin{array}{c}\text { Mexican } \\
\text { Immigrants: } \\
\text { mig. age }>=18\end{array}$} & \multicolumn{2}{|c|}{$\begin{array}{c}\text { Mexican } \\
\text { Immigrants, } \\
\text { mig. Age>=18, } \\
\text { in US at Least } \\
10 \text { Years }\end{array}$} & \multicolumn{2}{|c|}{$\begin{array}{c}\text { Second } \\
\text { Generation } \\
\text { Mexican } \\
\text { Americans }\end{array}$} & \multicolumn{2}{|c|}{$\begin{array}{c}\text { Third } \\
\text { Generation } \\
\text { Mexican } \\
\text { Americans } \\
\end{array}$} \\
\hline & men & women & men & women & men & women & men & women & men & women & men & women & men & women \\
\hline agriculture & 0.034 & 0.015 & 0.149 & 0.066 & 0.138 & 0.053 & 0.163 & 0.080 & 0.160 & 0.071 & 0.047 & 0.016 & 0.035 & 0.011 \\
\hline mining & 0.009 & 0.002 & 0.006 & 0.001 & 0.007 & 0.001 & 0.004 & 0.001 & 0.005 & 0.000 & 0.009 & 0.001 & 0.014 & 0.002 \\
\hline construction & 0.117 & 0.016 & 0.179 & 0.008 & 0.170 & 0.007 & 0.181 & 0.007 & 0.164 & 0.005 & 0.117 & 0.011 & 0.126 & 0.011 \\
\hline mfg, nondurable & 0.068 & 0.048 & 0.105 & 0.151 & 0.102 & 0.145 & 0.109 & 0.179 & 0.110 & 0.186 & 0.074 & 0.042 & 0.072 & 0.038 \\
\hline mfg, durable & 0.132 & 0.052 & 0.116 & 0.086 & 0.128 & 0.095 & 0.115 & 0.087 & 0.131 & 0.100 & 0.090 & 0.043 & 0.099 & 0.044 \\
\hline transportation & 0.057 & 0.024 & 0.036 & 0.012 & 0.046 & 0.014 & 0.031 & 0.010 & 0.041 & 0.012 & 0.068 & 0.022 & 0.062 & 0.022 \\
\hline commun, utilites & 0.035 & 0.017 & 0.007 & 0.005 & 0.009 & 0.005 & 0.006 & 0.003 & 0.006 & 0.003 & 0.029 & 0.016 & 0.033 & 0.025 \\
\hline wholesale trade & 0.051 & 0.025 & 0.043 & 0.036 & 0.048 & 0.038 & 0.043 & 0.037 & 0.048 & 0.041 & 0.051 & 0.028 & 0.052 & 0.023 \\
\hline retail trade & 0.160 & 0.210 & 0.208 & 0.247 & 0.185 & 0.219 & 0.202 & 0.235 & 0.176 & 0.197 & 0.216 & 0.268 & 0.200 & 0.245 \\
\hline $\begin{array}{l}\text { finance, real estate } \\
\text { and insurance }\end{array}$ & U5] & .083 & 015 & 0.031 & 019 & 0.039 & 4 & 0.022 & 020 & 0.026 & 0 & 3 & 3 & 1 \\
\hline business and repair & & & & & & & & & & & & كוס & كט & ז \\
\hline $\begin{array}{l}\text { servs } \\
\text { private houshold }\end{array}$ & 0.073 & 0.050 & 0.070 & 0.062 & 0.068 & 0.058 & 0.070 & 0.063 & 0.067 & 0.055 & 0.080 & 0.046 & 0.072 & 0.053 \\
\hline servs & 0.001 & 0.009 & 0.004 & 0.065 & 0.003 & 0.056 & 0.004 & 0.079 & 0.004 & 0.072 & 0.002 & 0.016 & 0.002 & 0.012 \\
\hline other personal servs & 0.006 & 0.021 & 0.006 & 0.038 & 0.006 & 0.037 & 0.007 & 0.043 & 0.006 & 0.045 & 0.007 & 0.022 & 0.008 & 0.021 \\
\hline $\begin{array}{l}\text { entertainment and } \\
\text { rec. servs }\end{array}$ & 0.022 & 0.021 & 0.016 & 0.009 & 0.016 & 0.010 & 0.016 & 0.008 & 0.017 & 0.009 & 0.024 & 0.019 & 0.020 & 0.020 \\
\hline health servs & 0.032 & 0.141 & 0.011 & 0.061 & 0.013 & 0.077 & 0.008 & 0.052 & 0.010 & 0.070 & 0.032 & 0.122 & 0.030 & 0.138 \\
\hline $\begin{array}{l}\text { education servs } \\
\text { other professional }\end{array}$ & 0.049 & 0.130 & 0.014 & 0.058 & 0.020 & 0.073 & 0.013 & 0.042 & 0.019 & 0.053 & 0.044 & 0.128 & 0.047 & 0.130 \\
\hline servs & 0.038 & 0.040 & 0.005 & 0.008 & 0.006 & 0.009 & 0.004 & 0.004 & 0.004 & 0.003 & 0.014 & 0.031 & 0.019 & 0.024 \\
\hline social servs & 0.016 & 0.057 & 0.006 & 0.044 & 0.008 & 0.048 & 0.006 & 0.042 & 0.008 & 0.044 & 0.016 & 0.056 & 0.017 & 0.062 \\
\hline public admin & 0.047 & 0.040 & 0.005 & 0.012 & 0.007 & 0.016 & 0.003 & 0.006 & 0.004 & 0.008 & 0.050 & 0.041 & 0.058 & 0.047 \\
\hline
\end{tabular}


Table A5: Industrial and Occupational Distribution by Gender (ctd)

\begin{tabular}{|c|c|c|c|c|c|c|c|c|c|c|c|c|c|c|}
\hline \multirow[t]{2}{*}{ Occupation } & \multicolumn{2}{|c|}{$\begin{array}{c}\text { White, } \\
\text { Nonhispanic } \\
\text { Natives with } \\
\text { Native Parents }\end{array}$} & \multicolumn{2}{|c|}{$\begin{array}{c}\text { Mexican } \\
\text { Immigrants }\end{array}$} & \multicolumn{2}{|c|}{$\begin{array}{c}\text { Mexican } \\
\text { Immigrants, in } \\
\text { US at Least } 10 \\
\text { Years }\end{array}$} & \multicolumn{2}{|c|}{$\begin{array}{c}\text { Mexican } \\
\text { Immigrants: } \\
\text { mig. age }>=18\end{array}$} & \multicolumn{2}{|c|}{$\begin{array}{c}\text { Mexican } \\
\text { Immigrants, } \\
\text { mig. age>=18, } \\
\text { in US at Least } \\
10 \text { Years }\end{array}$} & \multicolumn{2}{|c|}{$\begin{array}{l}\text { Second } \\
\text { Generation } \\
\text { Mexican } \\
\text { Americans }\end{array}$} & \multicolumn{2}{|c|}{$\begin{array}{l}\text { Third } \\
\text { Generation } \\
\text { Mexican } \\
\text { Americans } \\
\end{array}$} \\
\hline & men & women & men & women & men & women & men & women & men & women & men & women & men & women \\
\hline manager & 0.159 & 0.144 & 0.031 & 0.037 & 0.040 & 0.045 & 0.025 & 0.026 & 0.031 & 0.030 & 0.084 & 0.093 & 0.085 & 0.108 \\
\hline $\begin{array}{l}\text { professional \& } \\
\text { technical }\end{array}$ & 0.163 & 0.223 & 0.024 & 0.045 & 0.032 & 0.052 & 0.017 & 0.031 & 0.020 & 0.028 & 0.087 & 0.130 & 0.094 & 0.142 \\
\hline clerical & 0.052 & 0.245 & 0.025 & 0.108 & 0.032 & 0.133 & 0.017 & 0.060 & 0.021 & 0.067 & 0.080 & 0.303 & 0.077 & 0.292 \\
\hline sales & 0.122 & 0.136 & 0.038 & 0.090 & 0.044 & 0.092 & 0.032 & 0.064 & 0.037 & 0.066 & 0.108 & 0.168 & 0.091 & 0.146 \\
\hline personal service & 0.058 & 0.125 & 0.166 & 0.304 & 0.138 & 0.273 & 0.170 & 0.351 & 0.145 & 0.320 & 0.102 & 0.151 & 0.092 & 0.160 \\
\hline protective service & 0.026 & 0.006 & 0.005 & 0.003 & 0.007 & 0.003 & 0.002 & 0.002 & 0.003 & 0.002 & 0.031 & 0.008 & 0.038 & 0.007 \\
\hline health service & 0.003 & 0.029 & 0.002 & 0.032 & 0.002 & 0.041 & 0.001 & 0.030 & 0.001 & 0.043 & 0.005 & 0.038 & 0.005 & 0.045 \\
\hline farm manager & 0.014 & 0.005 & 0.005 & 0.001 & 0.005 & 0.001 & 0.005 & 0.002 & 0.006 & 0.002 & 0.003 & 0.001 & 0.002 & 0.001 \\
\hline farmworker & 0.023 & 0.006 & 0.151 & 0.075 & 0.136 & 0.063 & 0.168 & 0.092 & 0.160 & 0.087 & 0.049 & 0.014 & 0.038 & 0.008 \\
\hline craft & 0.194 & 0.019 & 0.231 & 0.049 & 0.243 & 0.050 & 0.235 & 0.052 & 0.247 & 0.055 & 0.192 & 0.021 & 0.216 & 0.022 \\
\hline $\begin{array}{l}\text { operative, exc } \\
\text { transportation equip. } \\
\text { transportation }\end{array}$ & 0.063 & 0.036 & 0.136 & 0.200 & 0.137 & 0.195 & 0.141 & 0.233 & 0.150 & 0.248 & 0.076 & 0.042 & 0.076 & 0.040 \\
\hline equipment operative & 0.067 & 0.009 & 0.066 & 0.006 & 0.080 & 0.007 & 0.060 & 0.005 & 0.074 & 0.004 & 0.075 & 0.010 & 0.088 & 0.009 \\
\hline laborer & 0.056 & 0.016 & 0.121 & 0.051 & 0.104 & 0.045 & 0.127 & 0.053 & 0.104 & 0.049 & 0.108 & 0.023 & 0.098 & 0.022 \\
\hline
\end{tabular}

Note: sample includes all workers with a reported occupation and industry for the previous year. 